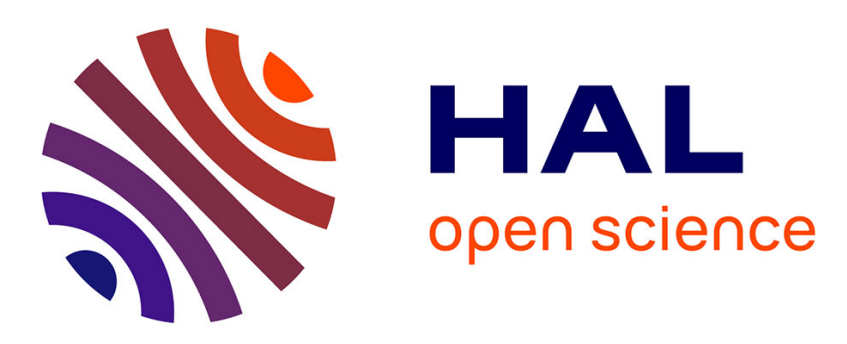

\title{
Suspension and near-bed load sediment transport processes above a migrating, sand-rippled bed under shoaling waves
}

\author{
David Hurther, Peter Derreck Thorne
}

\section{- To cite this version:}

David Hurther, Peter Derreck Thorne. Suspension and near-bed load sediment transport processes above a migrating, sand-rippled bed under shoaling waves. Journal of Geophysical Research. Oceans, 2011, 116, pp.C07001. 10.1029/2010JC006774 . hal-00607983

\section{HAL Id: hal-00607983 \\ https://hal.science/hal-00607983}

Submitted on 11 Jul 2011

HAL is a multi-disciplinary open access archive for the deposit and dissemination of scientific research documents, whether they are published or not. The documents may come from teaching and research institutions in France or abroad, or from public or private research centers.
L'archive ouverte pluridisciplinaire HAL, est destinée au dépôt et à la diffusion de documents scientifiques de niveau recherche, publiés ou non, émanant des établissements d'enseignement et de recherche français ou étrangers, des laboratoires publics ou privés. 


\title{
Suspension and near-bed load sediment transport processes above a migrating, sand-rippled bed under shoaling waves
}

\author{
D. Hurther ${ }^{1}$ and Peter D. Thorne ${ }^{2}$ \\ Received 30 October 2010; revised 14 March 2011; accepted 31 March 2011; published 1 July 2011.
}

[1] The present study focuses on the fine-scale flow and sand transport processes above onshore migrating ripples below skewed surface gravity waves in the shoaling zone. A set of acoustic instruments was deployed in the shoaling region of the large-scale wave channel at Canal d'Investigacío i Experimatacío Marítima, Universitat Poltiècnica de Catalunya, Barcelona, Spain, in order to provide high-resolution velocity and sediment concentration profiles with an acoustic concentration and velocity profiler (ACVP). Measurements are analyzed relative to the positions of the measured nonmoving sand bed and the interface separating the suspension from the near-bed load layer. This interface is detected here by the application of a novel acoustic bed echo detection method. Furthermore, the use of the dual-frequency inversion proposed in the work of Hurther et al. (2011) allows for the calculation of the sediment concentration profile across both the suspension and near-bed load layers. The sand bed was covered by quasi-two-dimensional suborbital ripples migrating onshore. As proposed by O'Donoghue et al. (2006), the occurrence of quasi-two-dimensional ripples is attributed to the fine-size sand of $D_{50}=250 \mu \mathrm{m}$ used in the present study under full-scale forcing conditions. In order to determine the effect of shoaled wave skewness on the ripple vortex entrainment and sediment transport, the instantaneous and mean measurements of the flow, sediment concentration, and sediment flux along the ripple profile are discussed in terms of (1) the occurrence of ripple vortex entrainment on either side of the ripple crest; (2) the wave velocity phase lagging driven by the ripple vortex entrainment process and the turbulent bed friction effects in the wave boundary layer; (3) phase lagging between velocity and maximum concentration and sediment flux events; (4) the structure of bed friction and ripple-driven turbulence across the suspension and the near-bed load layers; and (5) the streaming components. The results on these aspects strongly support that the wave velocity skewness effect under shoaling waves is fairly similar to the one obtained in skewed oscillatory water tunnel flows. Furthermore, it is found that the onshore-oriented net bed load sediment transport is at the origin of the onshore ripple migration. This flux is roughly twice as much as the opposite offshore-oriented net suspension flux dominated by the ripple vortex entrainment processes.

Citation: Hurther, D., and P. D. Thorne (2011), Suspension and near-bed load sediment transport processes above a migrating, sand-rippled bed under shoaling waves, J. Geophys. Res., 116, C07001, doi:10.1029/2010JC006774.

\section{Introduction}

[2] Wave induced sand ripples with typical sizes of $\mathrm{O}$ $(1-10 \mathrm{~cm})$ in height and $\mathrm{O}(0.1-1 \mathrm{~m})$ in length are common bed form features across the coastal nearshore region [Traykovski et al., 1999; Smyth et al., 2002; Williams et al., 2003]. They are typically found on the flat continental shelf region, the shoaling region or the inner surf zone where the local mobility number $\psi$ do not exceed the critical value of about 200. This value is commonly accepted as the upper limit of the ripple vortex regime and the lower limit for the

\footnotetext{
${ }^{1}$ Laboratory of Geophysical and Industrial Flows, Université de Grenoble, CNRS, Grenoble, France.

${ }^{2}$ National Oceanography Centre, Liverpool, UK.

Copyright 2011 by the American Geophysical Union. 0148-0227/11/2010JC006774
}

initiation of the sheet flow regime [Nielsen, 1992]. In the latter case, ripples are no longer present because they are removed by the movement of the sediments as a sheet layer over a thickness of up to few centimeters above the undisturbed sandbed. This situation generally occurs in the shallower wave breaking zone (or outer surf zone) and swash zones, whereas the ripple vortex regime can dominate the net sediment transport in the deeper shoaling and in the inner surf zone (with weaker wave breaking effects) when the mean ripple slope, $\eta / \lambda$, exceeds a value of roughly $10 \%$, where $\eta$ and $\lambda$ are the ripple height and wavelength, respectively. Following the ripple type classification proposed by Wiberg and Harris [1994], ripples commonly seen in the shoaling zone are of orbital or suborbital types $\left(d_{0} / D_{50}<5500\right.$, the ratio between the near-bed orbital diameter, $d_{0}$, and the median sediment size, $D_{50}$ ) because the wave induced bed shear stress is dominant over the one generated by currents. In the surf 
zone, ripples can be of anorbital type $\left(d_{0} / D_{50}>5500\right)$ implying that the mean ripple dimensions are not scaling with the orbital excursion at the bed, but in common with current ripples, with the grain size. These anorbital ripples are generally intermittent at the intrawave timescale, disappearing due to the strongest bed shear stresses and reappearing during periods of weaker stress.

[3] The study of O'Donoghue et al. [2006] revisited the validity of ripple shape classification and ripple size prediction formulas based on a large data set of full-scale water tunnel flows and one large-scale wave channel test. The measurements obtained under full-scale conditions showed significant differences in terms of ripple size compared with earlier results obtained in small-scale installations. In particular, ripple height and length in the range of suborbital and anorbital ripples $\left(d_{0} / D_{50}>1750\right)$ showed higher values than the model results of Wiberg and Harris [1994]. Some of these model prediction limitations have been corrected on the basis of field measurements of ripples [Traykovski et al., 1999; Traykovski, 2007]. Full-scale conditions appear therefore as an important experimental parameter to capture the right dynamics of orbital and suborbital ripples and this is of interest here.

[4] Another aspect pointed out in the work of O'Donoghue et al. [2006] is the lack of equilibrium ripple data carried out with sand of median size in the range of $220 \mu \mathrm{m}<D_{50}<$ $330 \mu \mathrm{m}$ under full-scale controlled conditions. Whether 2-D or 3-D ripples occur under these conditions is unclear at present and requires further experiments. Such experiments could help to reinforce the observation by O'Donoghue et al. [2006] that the occurrence of 3-D ripples under full-scale conditions is not a question of the range of the critical normalized orbital diameter [Carstens et al., 1969; Sato and Horikawa, 1986] nor of critical mobility number value [Lofquist, 1978], but rather relies on the sediment size with a tendency to observe 3-D ripples when $D_{50}<220 \mu \mathrm{m}$ and fully established 2-D ripples for $D_{50}>330 \mu \mathrm{m}$.

[5] The study by van der Werf et al. [2007] has provided new data related to the ripple vortex entrainment process and its contribution to sediment transport by exploring the finescale $2-\mathrm{D}$ velocity field and the suspended sediment concentration, SSC, profiles under full-scale oscillatory water tunnel flows above 2-D ripples. The study addressed the effects of the velocity asymmetry parameter $R$, defined as $R=\left(u_{1}+u_{2}\right) / 2 u_{1}$, typical for second-order Stokes waves in the shoaling zone. Here $u_{1}$ and $u_{2}$ are the amplitudes of the first- and second-order oscillatory modes of the Stokes wave, respectively. This parameter, which is a measure of the nonlinear topographical shoaling effect under surface gravity waves can be set arbitrarily over a wide range of values for oscillatory flows in water tunnels (also called U tubes). Its influence on the suspended and total net sediment fluxes, ripple entrainment process and ripple migration has been analyzed for a wide range of full-scale oscillatory flows in the ripple vortex regime. In particular, van der Werf et al. [2007] demonstrated that velocity skewness induces a net suspended load flux in the offshore direction while the net bed load sediment flux was onshore with a corresponding onshore ripple migration. Field evidence of opposite net sediment fluxes between the offshore-oriented suspension load and the onshore-oriented bed load, has also been shown by Traykovski et al. [1999] in a ripple vortex regime below velocity skewed waves and sand of similar median grain size of $D_{50} \approx 400 \mu \mathrm{m}$. At high asymmetry values $(R=0.59)$, the total net sediment flux measured in the work of van der Werf et al. [2007]; that is, the time and space integrated suspended and bed load sediment fluxes, was shown to be directed offshore and associated with the dominant role played by ripple vortex transport being larger than the bed load transport. This ripple vortex dominated transport occurred for values of the ratio between ripple height and mean sand size $P=\eta / D_{50}$, greater than the transitional range of 70-90 in agreement with earlier findings of van der Werf et al. [2006]. Because the velocity and SSC data were obtained from spatially separated PIV and SSC measurements in the work of van der Werf et al. [2007] and at a temporal resolution too low to resolve turbulent flow scales, this analysis could not address streaming effects due to turbulence. Furthermore, the bed load transport could only be deduced indirectly from a mass balance between the acoustically measured suspension load and the total load estimated with sediment traps at both ends of the water tunnel.

[6] In order to overcome these measurement limitations, the present study uses a multifrequency acoustic concentration and velocity profiler (ACVP) recently developed within the project Hydralab III-SANDS [Hurther and Lemmin, 2008; Hurther et al., 2011; P. D. Thorne et al., Acoustic inversions for measuring boundary layer suspended sediment processes, submitted to Journal of the Acoustical Society of America, 2011]. This measuring tool combines ADVP [Hurther and Lemmin, 2001] with ABS technology [Thorne and Hanes, 2002] in a single system and has the capability of measuring colocated and simultaneously, high-resolution profiles of two-component velocity and suspended sediment concentration in the suspension layer and in the near-bed load above the sand bed detected as the nonmoving bed interface as described in section 3. The high-concentration region was identified in the acoustic backscatter signal within $0.01-$ $0.02 \mathrm{~m}$ of the bed which we have labeled here as the near bed load. We have explicitly not used the term bed load because it is not clear that this region is associated with rolling, sliding, and/or saltating. On the basis of these measurement performances, the sand fluxes in the vertical and the cross-shore directions could be profiled along a migrating ripple with a spatial-temporal resolution allowing the calculation of current, wave and turbulence related components.

[7] Considering the previous published results and the available measurement performances, the present study had a number of objectives which are outlined here. First are the details of ripple vortex entrainment under full-scale surface gravity waves in the shoaling zone; that is, where the wave asymmetry is not forced as in oscillatory water tunnel flows but results from the nonlinear interactions between the wave harmonic components due to topographical changes in the shallower shoaling region. This condition necessitates the experiments to be carried out in a large-scale wave flume. The streaming processes of the flow and the sediment transport components under these waves will be compared to the ones reported by van der Werf et al. [2007, 2008] under skewed oscillatory flow conditions. Second to identify the type of ripples (shape and class following the classification suggested in the work of Wiberg and Harris [1994]) generated under full-scale gravity waves in the shoaling zone for a sand of 

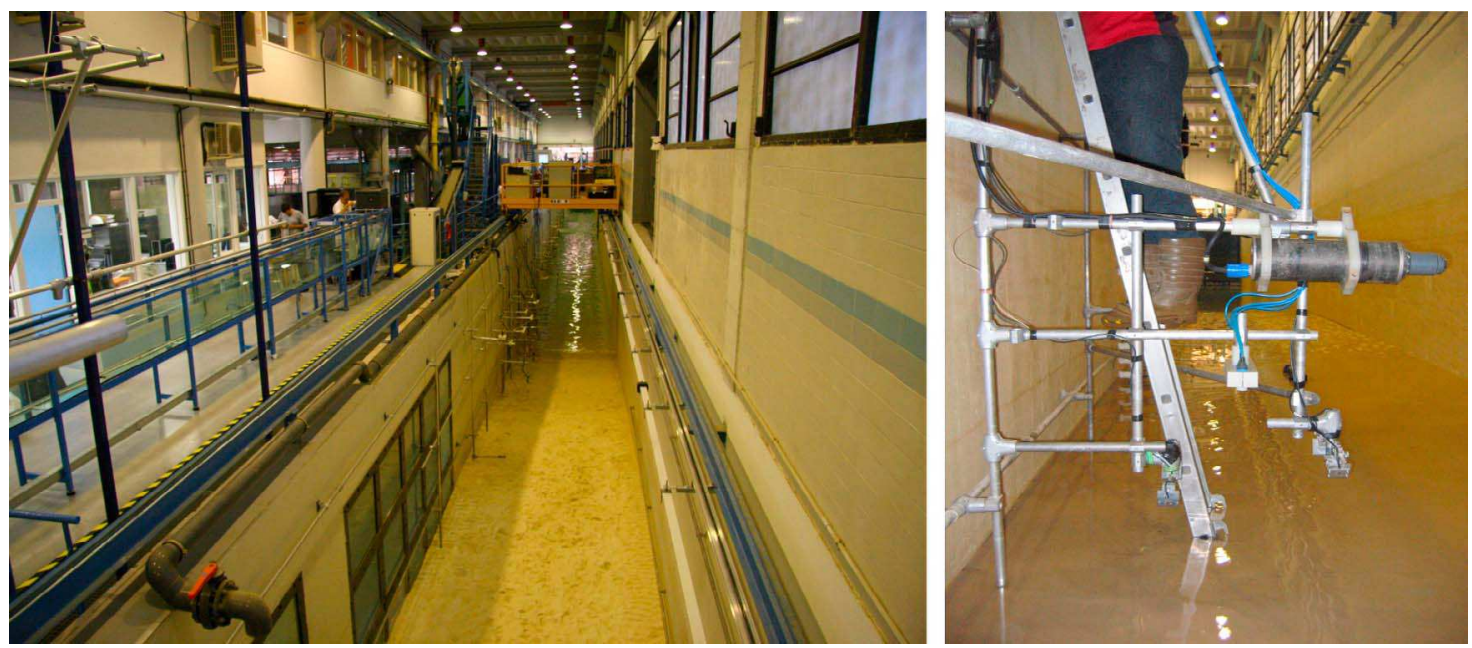

Figure 1. Photographs of (left) the $100 \mathrm{~m}$ long, $3 \mathrm{~m}$ wide, and $5 \mathrm{~m}$ deep wave channel at UPC-CIEM, Barcelona, Spain, and (right) the experimental arrangements of the instruments.

median size in the range of $220 \mu \mathrm{m}<D_{50}<300 \mu \mathrm{m}$. O'Donoghue et al. [2006] identified this range of flow conditions as relatively unexplored in the literature and therefore would fill a gap of realistic nearshore flow conditions. For this purpose the measurements of ripple height and wavelength were measured using an acoustic ripple profiler (ARP) [see Williams et al., 2004]. Third because the nonmoving bed position below the velocity and SSC profiles could also be determined, we were interested in the vertical structure of the mean flow, turbulence, SSC and sediment flux relative to the nonmoving sand bed. In particular, we were interested in the vertical structure across both the suspension and near-bed sediment loads of the turbulent flow field and the sediment transport quantities particularly in terms of turbulence anisotropy and damping effects. This aspect is relevant to the type of turbulence closures being used in numerical models for the prediction of suspension and near-bed load sediment transport above migrating ripples under asymmetric shoaling waves.

\section{Experimental Conditions}

\subsection{Experimental Setup and Instrumentation}

[8] The experiments were carried out in the large-scale wave channel, shown in Figure 1, at the Catalonia Polytechnic University in Barcelona, Spain, during October 2008. The dimensions of the flume were $100 \mathrm{~m}$ long, $3 \mathrm{~m}$ wide and $5 \mathrm{~m}$ deep and the wave paddle characteristics at the deep water end of the channel were designed to establish nearly full-scale gravity wave conditions.

[9] Mobile bed experiments with sand were conducted to generate full-scale bed ripples under skewed waves in the shoaling region. As mentioned in the introduction, the difference between the experimental conditions obtained here and in full-scale oscillatory flow experiments conducted in closed U tube tunnels [O'Donoghue et al., 2006; van der Werf et al., 2007; Ribberink et al., 2008], resides in the topographic origin of the wave transformation from a nearly monochromatic shape in the deep channel region to an asymmetric waveshape in the shallower shoaling region. As a result, this nonlinear wave transformation process is similar to that which real progressive waves undergo on approaching the nearshore region, as opposed to the forcing being imposed in closed oscillating tunnels. These two experimental conditions differ in terms of the vertical flow velocity component which is negligibly small in the closed water tunnel), while in open large-scale channels the vertical flow may induce differences in the ripple entrainment process and the boundary layer streaming.

[10] At the beginning of the experiment program a sand bed of $50 \mathrm{~cm}$ thickness was deposited in the channel, this formed a sand bed over half of the channel length at the onshore end. An initial constant beach slope of $1 / 15$ was leveled manually over $30 \mathrm{~m}$. In order to generate a more natural and stable beach profile, 15 series of irregular JONSWAP waves were first generated over $\sim 7 \mathrm{~h}$. Once a slowly evolving beach profile composed of a fairly stable breaking bar was established, two $30 \mathrm{~min}$ long sequences of the desired regular wave sequence were required to develop equilibrium orbital ripples. The measurements were acquired over two consecutive 30 min long regular wave sequences. The moderately wellsorted sand $\left(D_{90} / D_{10}=2.4\right)$ of median diameter $D_{50}=250 \mu \mathrm{m}$ was chosen to fill a gap of full-scale ripple regime conditions in the range $220 \mu \mathrm{m}<D_{50}<330 \mu \mathrm{m}$ as previously outlined in the work of O'Donoghue et al. [2006].

[11] The experimental setup is shown in Figure 2a. To measure the bed forms an ARP [Williams et al., 2004], based on a rotary narrow beam profiler, was used to measure the height of the sand surface over a $2.0 \mathrm{~m}$ transect. Transects were collected each minute during the data collection periods, which were typically about $30 \mathrm{~min}$. As shown in Figure $2 \mathrm{~b}$ two synchronized multifrequency acoustic concentration and velocity profilers (ACVPs) were deployed at 32 and $42 \mathrm{~cm}$ above the bed to profile the two-component pulse-coherent velocity and the suspended sediment concentration profiles simultaneously in the same sample volumes [Hurther et al., 2011]. The ACDP transmission rate was $1000 \mathrm{~Hz}$ and these data were processed to give cross-shore, $u$, and vertical, $w$, velocity components and sediment concentration profiles at a temporal resolution of $25 \mathrm{~Hz}$ with a vertical spatial resolution of $3 \mathrm{~mm}$. Figure $2 \mathrm{~b}$ shows the ACVP configuration and installation. 


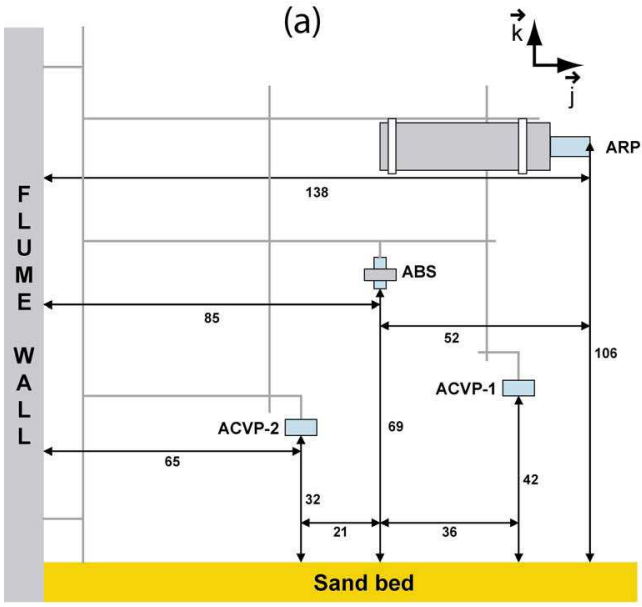

(b)

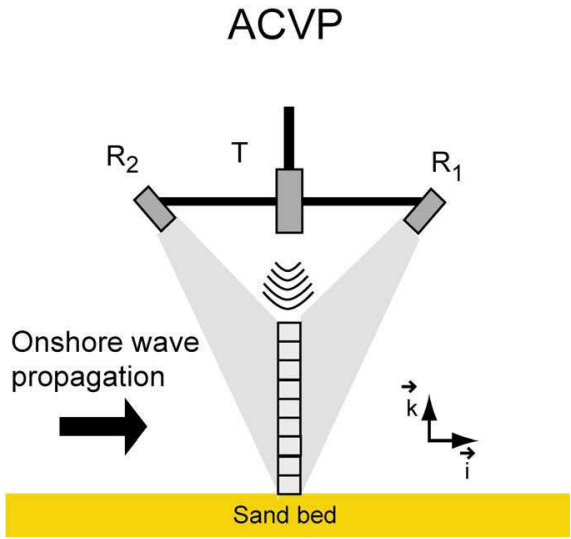

Figure 2. (a) Set of deployed acoustic instruments composed of an acoustic ripple profiler (ARP), one acoustic backscatter system (ABS), and two acoustic concentration and velocity profilers (ACVPs). Onshore flow is out of the paper. (b) Configuration of an ACVP with $T, \mathrm{R}_{1}$, and $\mathrm{R}_{2}$ being the piezoelectrical transmitter, the onshore side receiver, and offshore side receiver, respectively.

[12] In order to determine the inversion constants of the ACVP necessary for the concentration calculation, an acoustic backscattering system (ABS) [see Hay and Sheng, 1992; Crawford and Hay, 1993; Thorne and Hanes, 2002] operating at $0.5,1.0,2.0$ and $4.0 \mathrm{MHz}$ was used following the methodology described in the work of Thorne and Hurther [2009]. Once the ACVP system constants and the acoustic sand properties were determined, the dual-frequency inversion method proposed in the work of Hurther et al. [2011] was applied to the ACVP backscattered signal. Compared to the well-known implicit iterative [Thorne et al., 1993] and the explicit inversions [Lee and Hanes, 1995], this technique offers the unique advantage of being unaffected by the nonlinear sediment attenuation effect across highly concentrated flow regions [Hurther et al., 2011; Thorne et al., submitted manuscript, 2011]. As a result, stable sand concentration profiles with values up to $70 \mathrm{~kg} \mathrm{~m}^{-3}$ were obtained in the Oscillating Grid Tank experiment in the work of Hurther et al. [2011]. In the present study, the dual-frequency inversion method is applied for the first time to the highly concentrated near-bed load region. It is readily acknowledged that the incoherent scattering theory used to interpret the ACVP backscatter data did not include multiple scattering effects. However, we assume that to a first approximation the approach was valid for the present study where near-bed conditions had a maximum concentration of around $100 \mathrm{~kg}$ $\mathrm{m}^{-3}$ which is less than $4 \%$ volume concentration. As discussed in section 6, the good agreement between the net near-bed load transport obtained from the independent ACVP and ARP measurements strongly supports the validity of the concentration values obtained in the near-bed load layer.

[13] Another specific acoustic benthic interface detection method was applied here for the first time. This consisted of identifying in the backscattered signal profile the nonmoving bed echo characterized by its immobility and the echo at the maximum suspended sediment concentration. These two near-bed echoes can be separated when the acoustic intensity profile is derived from the demodulated Doppler signals since the acoustic scatterers constituting the nonmoving sandbed produce a constant voltage with negligible signal variance. As a result the time evolution of the nonmoving sand bed, the overlaying high-concentration layer, called in the present study the near-bed load layer, and the suspended sediments can be identified and both the velocity and the sediment concentration data discussed in relationship to these three zones and their interface positions. Whether the region in between the two interfaces corresponds to the bed load layer could not be demonstrated explicitly here but several results presented below strongly supports this hypothesis. In particular the good agreement between the near-bed load transport estimated from the sediment flux measurement and from the ripple shape measurements support the bed load hypothesis. Nevertheless, the term near-bed load has been used instead of bed load since further tests are required to confirm this relevant point. Although this novel methodology is still under development, it was decided to present and apply it here because of its significance and potential to the present and future sediment transport studies.

[14] Recently, Jaramillo et al. [2009] have used an acoustic method for distinguishing the acoustic bottom echo from the lutocline position in near-bed mudflow conditions. Their method is different in the sense that it combines both backscattered intensity and velocity signals measured in separate sample volumes by an ABS and a Pulse Coherent-Acoustic Doppler Profiler (PC-ADP). The method developed in the study reported here has the advantage that it only relies on the backscattered intensity calculated from the demodulated Doppler signals. The vertical resolution of $3 \mathrm{~mm}$ is therefore the same for the velocity and the sediment concentration profilings.

\subsection{Mean Wave, Sediment Transport, and Ripple Characteristics}

[15] Table 1 summarizes the important mean flow parameters of the ripple vortex experiment. In the deep water region close to the piston wave-maker, the water depth, wave period and wave height were set to $h=1.9 \mathrm{~m}, T=6.5 \mathrm{~s}$ and $H_{0}=$ $50 \mathrm{~cm}$, respectively. At the measurement site in the shoaling 
Table 1. Mean Wave and Ripple Characteristics

\begin{tabular}{lc}
\hline Parameter & Value \\
\hline$T(\mathrm{~s})$ & 6.5 \\
$H_{0}(\mathrm{~m})$ & 0.5 \\
$H(\mathrm{~m})$ & 1.9 \\
$u_{1}\left(\mathrm{~m} \mathrm{~s}^{-1}\right)$ & 0.44 \\
$u_{2}\left(\mathrm{~m} \mathrm{~s}^{-1}\right)$ & 0.15 \\
$u_{r m s}\left(\mathrm{~m} \mathrm{~s}^{-1}\right)$ & 0.38 \\
$d_{0}(\mathrm{~m})$ & 1.1 \\
$R$ & 0.61 \\
$S_{u}$ & 0.34 \\
$D_{50}(\mu \mathrm{m})$ & 250 \\
$\eta(\mathrm{cm})$ & 2.9 \\
$\lambda(\mathrm{cm})$ & 25 \\
$\eta / \lambda$ & 0.11 \\
$\Psi$ & 70 \\
$d_{0} / D_{50}$ & 4400 \\
$c_{r}\left(\mathrm{~cm} \mathrm{mn}{ }^{-1}\right)$ & $1.4-1.6$ \\
\hline
\end{tabular}

region, the amplitudes of the second-order Stokes wave approximation at $30 \mathrm{~cm}$ above the bed and outside the bed form and wave boundary layer, WBL, affected region, were 0.44 and $0.15 \mathrm{~m} \mathrm{~s}^{-1}$, for the first- and second-order terms, respectively. This resulted in a velocity skewness $R=\left(u_{1}+\right.$ $\left.u_{2}\right) / 2 u_{1}$ of 0.61 which is typical of shoaled waves before breaking. The statistical third-order moment of the measured velocity $S_{u}=\overline{(u-\bar{u})^{3}} / u_{r m s}^{3}$ is equal to 0.34 . The corresponding orbital diameter $d_{0}=\sqrt{2} u_{r m s} T / \pi$ was about $1 \mathrm{~m}$ revealing the nearly full-scale regime for a root mean square wave velocity of $0.38 \mathrm{~m} \mathrm{~s}^{-1}$. The mobility number $\psi=\rho u_{r m s}^{2}$ $\left(\rho_{s}-\rho\right) g D_{50}$ had a value of 70 consistent with high sediment mobility flow conditions in the range of the ripple vortex regime and far below the initiation of the sheet flow regime. The parameters $\eta$ and $\lambda$ in Table 1 correspond to the ripple height and length, respectively. Their ratio $\eta / \lambda$ has a value of 0.11 above the critical value of $\sim 0.1$ for the initiation of the ripple vortex regime [Thorne et al., 2009]. Following the ripple classification of Wiberg and Harris [1994], the ratio $d_{0} / D_{50}=4400$ is in the range of suborbital ripples. O'Donoghue et al. [2006] argued that under full-scale flow forcing conditions, the orbital ripple regime for which the ripple dimensions, $\eta$ and $\lambda$, increase with $d_{0} / D_{50}$, is found to extend into the range of suborbital ripples as defined by Wiberg and Harris [1994]. Finally, a mean onshore-oriented ripple migration speed varying between +14 to $+16 \mathrm{~mm}$ min $^{-1}$ was measured using the ARP data as indicated in Figure 3. van der Werf et al. [2007] obtained a fairly close value in oscillatory flows under quite similar forcing conditions (called experiment Mr5c63) in terms of mobility number $\psi(=61)$ and skewness $R(=0.59)$.

[16] The time evolution of the ripple transects measured with the ARP is shown in Figure 3. Following the ripple morphology classification proposed in the work of O'Donoghue et al. [2006], the type of orbital ripples measured in our full-scale wave conditions correspond to quasi$2-\mathrm{D}$ ripples. The classification as quasi-2-D means that the length of the crest is at least 3-5 times longer than the ripple length. O'Donoghue et al. [2006] revisited the empirical formulation for the prediction of ripple height and length based on the analysis of a large set of literature ripple vortex data obtained in full-scale forcing conditions. They proposed the best fit formulations $\eta / d_{0}=0.5\left(0.151-0.012 \psi_{\max }^{0.42}\right)$ and $\lambda / d_{0}=0.5\left(1.44-0.32 \psi_{\max }^{0.21}\right)$ for $3-\mathrm{D}$ ripples obtained in the range $D_{50}<220 \mu \mathrm{m}$. When applied to our data we obtain the values $\eta=3.7 \mathrm{~cm}$ and $\lambda=33 \mathrm{~cm}$ which are about $20 \%$ and $25 \%$ higher, respectively, than the measured values in Table 1. As a result, it appears from the present results that the range of quasi-2-D/3-D orbital ripples is extended from $D_{50}<220 \mu \mathrm{m}$ to $D_{50}<250 \mu \mathrm{m}$ completing a gap in ripple vortex conditions as reported in the work of O'Donoghue et al. [2006].

[17] As described in section 2.1, the ACVP measurements were made at a fix position in the shoaling zone of the channel providing Eulerian measurements of velocity, sediment concentration and bed interfaces positions with $z$ and time. The data discussed below focuses on the analysis of these measured quantities over a period of time corresponding to the onshore migration of an entire ripple profile beneath the ACVP. Because the ripple migration speed is three orders of magnitude smaller than the wave velocity, the onshore migration distance over a period of four consecutive waves ranges from 5 to $7 \mathrm{~mm}$. As a result, phase averaging the measured quantities over four wave periods is equivalent to averaging the data spatially over this distance which is considered here as sufficiently small to resolve the fine-scale flow processes including the turbulent scales. Because the spatial distribution along the ripple profile is of great interest and can be compared directly to PIV literature results over a ripple length, time is converted into ripple length normalized position as $x / \lambda=\left(\lambda-i \delta t c_{r}\right) / \lambda$ with $\delta t=4 T$ and $i=1 . . T_{R} / \delta t$. $T_{R}$ is the time needed for a ripple to migrate below the ACVP which in our case was about $15 \mathrm{~min}$. This transformation relies on the assumption of constant ripple migration speed. As will be seen from comparison of our results with recent 2-D PIV measurements along a ripple profile, this assumption is strongly supported here.

\section{Ripple Vortex Entrainment at the Intrawave Scale}

[18] Evidence of the occurrence of ripple vortex generation, entrainment and impact on suspended sediment transport was examined at the intrawave scale using the velocity, SSC and

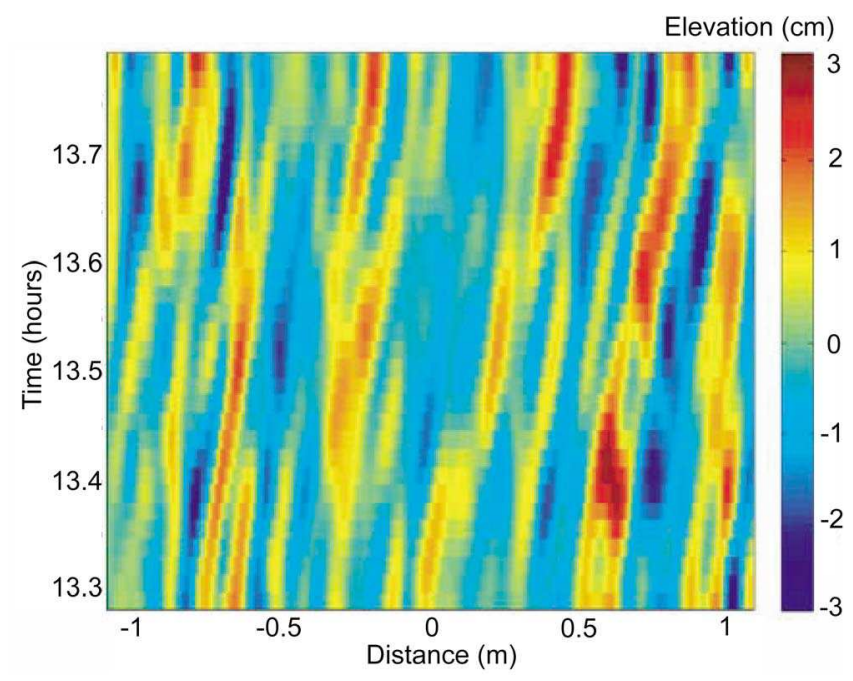

Figure 3. Bed elevation measurement with acoustic ripple profiler. The ripples migrated shoreward in the positive flow direction. 
(a)

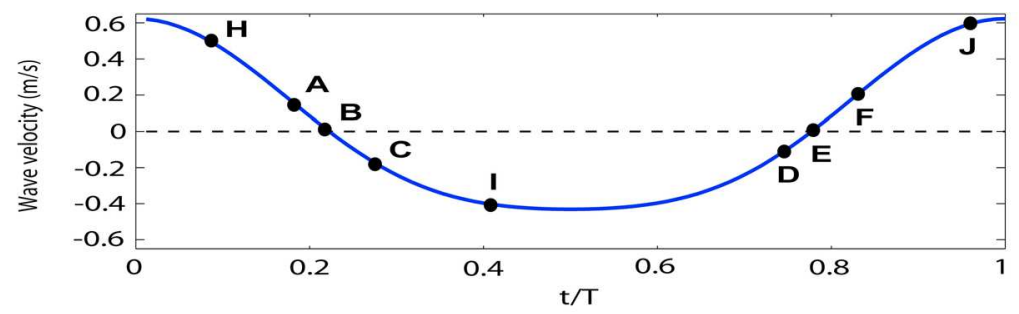

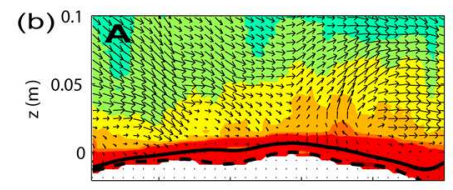

(c)
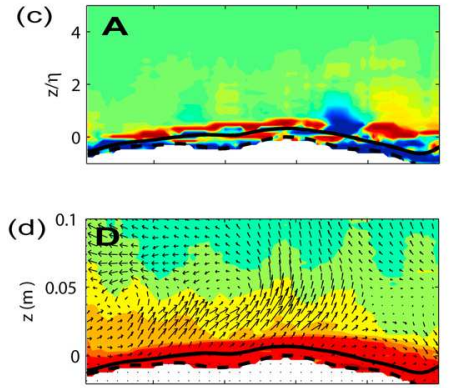

(e)
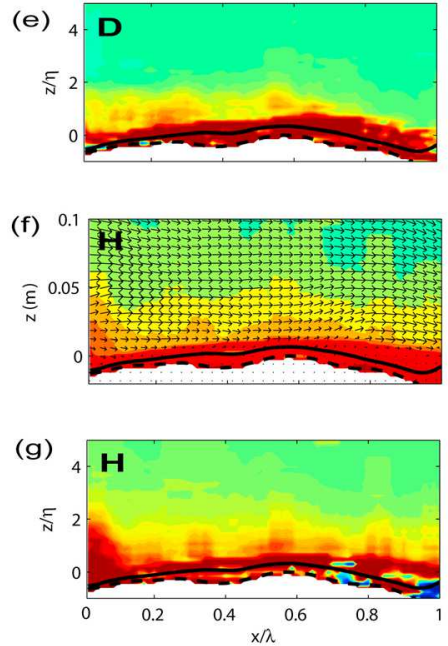
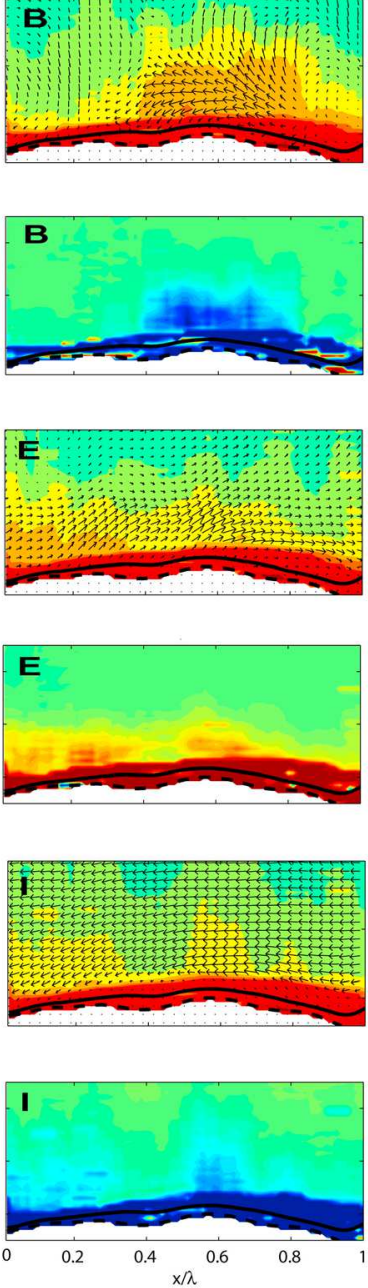

$\log _{10}[\mathrm{c}]$ in $\left(\mathrm{kg} \cdot \mathrm{m}^{-3}\right)$
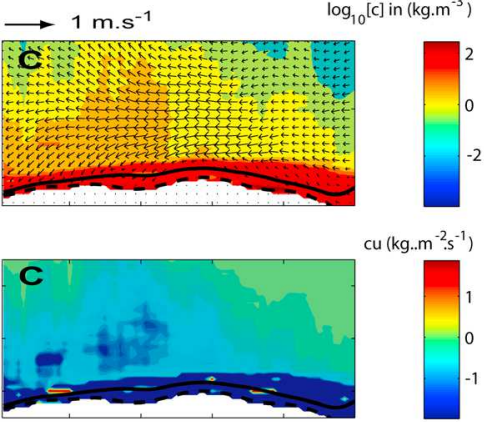

$\mathrm{cu}\left(\mathrm{kg} . \mathrm{m}^{-2} \mathrm{~s}^{-1}\right)$
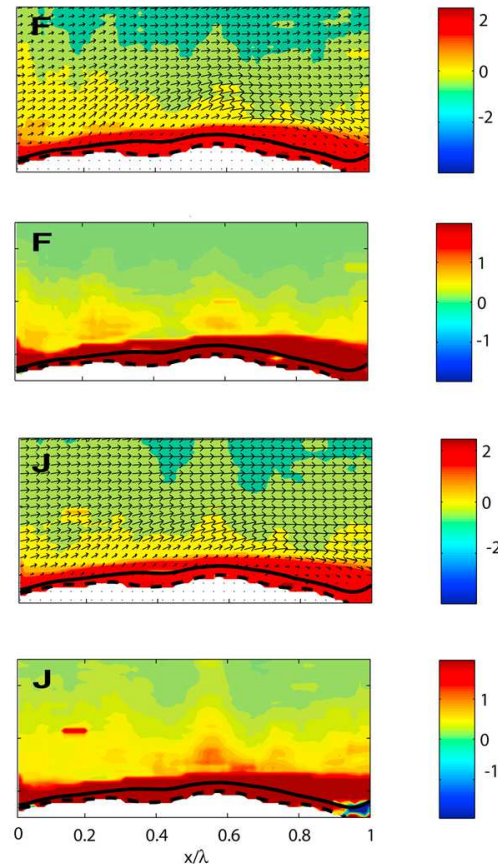

Figure 4. (a) Free-stream orbital velocity with positive flow onshore. (b, d, f) The velocity field $V(u, w)$ overlaid onto a color plot of $\log _{10}(c)$, the suspended concentration, and (c, e, g) color plots of the crossshore sediment flux $c u$ for each sequence. In each color plot the thick solid line corresponds to the interface between the near-bed load and suspension layer, and the dashed line between the near-bed load and the nonmoving sand bed.

sediment flux data measured along a complete ripple that migrated below the ACVP over $\sim 15$ min. Using the timespace conversion described above, all plots show the measured quantities in a vertical plane aligned with the onshore wave propagation. In the following, we define the lee side of the ripple as the onshore slope at the right-hand side of the ripple crest whereas the stoss side is defined as the offshore slope of the ripple on the left-hand side of the ripple crest. This definition is taken with regard to the onshore wave propagation.
[19] In Figure 4, measurements from the ACVP of velocity, SSC and sediment flux are presented. Figure 4 is structured to show these quantities around peak flow and at flow reversal. As shown in Figure 4a, the data analyzed were chosen at particular phases of the wave cycle measured by the ACVP at $0.25 \mathrm{~m}$ above the ripple crest outside the wave boundary layer. Three consecutive sequences around the onshore/ offshore flow reversal labeled $u_{+r}$ (A, B and C), 3 consecutive sequences around the offshore/onshore flow reversal labeled $u_{-r}(\mathrm{D}, \mathrm{E}$ and $\mathrm{F}$ ) and 3 sequences around the wave 
crest labeled $u_{+}(\mathrm{H}$ and $\mathrm{J})$ and the wave trough named $u_{-}$ (sequence I). For all sequences, the data have been phase averaged over 4 consecutive regular waves and the $2-\mathrm{D}(\mathrm{u}, \mathrm{w})$ velocity vector field has been superimposed onto color plots of the $\log _{10}(c)$ field, $c$ corresponding to the sand mass concentration. Furthermore, for each flow sequence, the color plot of the cross-shore sediment flux is represented in a separate plot. The thick dashed and solid black lines in all plots represent the nonmoving sand bed near-bed load interface and the near-bed load/suspension interface, respectively, identified using methods described in section 2 . The vertical axis in the velocity vector plots correspond to the distance in meters from the ripple crest (taken as the reference $z=0$ ) whereas in the color plots of the sediment flux, the vertical axis is the ripple height normalized distance from the ripple crest. These vertical axes provide the reader with both the dimensional and dimensionless distances.

[20] In Figure $4 \mathrm{~b}$ for sequence $\mathrm{A}$ just before $u_{+r}$, the velocity field reveals the presence of a clockwise rotating lee-side vortex at $x / \lambda=0.8$ and $z=2 \mathrm{~cm}$ (i.e., $z / \eta=0.66$ ). In the near-bed region for $z / \eta<2$, the flow field shows a rather heterogeneous spatial structure in terms of direction and amplitude for sequence A compared to sequences H, I, J. This is typical for a strong turbulent activity during flow reversals as will be shown quantitatively in section 4 . The SSC at sequence A shows a high-concentration region in the vicinity of the lee-side vortex whereas lower SSC is observed on the stoss side of the ripple. In the following sequence B, a strong return flow with upward oriented velocity can be seen around the ripple crest. This event entrains a spatially well defined SSC cloud into suspension up to a height of about $3 \eta$ above the ripple crest. In sequence $\mathrm{C}$, this $\mathrm{SSC}$ cloud is seen to be advected in the offshore direction under the effect of the spatially uniform wave trough velocity in the offshore direction. The cross-shore sediment flux sequences around $u_{+r}$ are shown in Figure 4c. At sequence A, the strong crossshore sediment fluxes are mainly limited to the near-bed load layer, in between the dashed and solid lines, in the onshore direction, except close to the lee-side vortex where the high sediment flux events are detected in the suspension region well above the solid black line and are directed offshore. It is quite convincing to appreciate the coherence between the regions of onshore and offshore-oriented sediment flux in Figure 4c and the onshore and offshore parts of the ripple vortex seen in Figure $4 \mathrm{~b}$, respectively. The sediment flux structure during the following sequences $\mathrm{B}$ and $\mathrm{C}$ of Figure $4 \mathrm{c}$ clearly reveal that the sediment cloud entrained into suspension by the ripple vortex at $u_{+r}$ is subsequently advected in the offshore direction. This process is seen to affect the offshore-oriented suspended sediment flux over a distance of up to $4 \eta$ above the ripple crest.

[21] The flow sequences D, E, F around the $u_{-r}$ reversal are shown in Figures $4 \mathrm{~d}$ and $4 \mathrm{e}$. The stoss-side ripple vortex with counter-clockwise rotation can be distinguished at location $x / \lambda=0.2$ and $\mathrm{z}=4 \mathrm{~cm}$ in Figure $4 \mathrm{~d}$, sequence D. Below at the right side of the stoss-side ripple vortex, a strong upward and onshore-oriented near-bed flow region is detected all along the stoss side of the ripple. This flow is much weaker below the solid line supporting a strong velocity damping effect in the near-bed load layer. At sequence D, the SSC in Figure 4d shows high SSC values around the ripple vortex region. However, this suspended sediment cloud does not persist in time during the subsequent sequences $\mathrm{E}$ and $\mathrm{F}$ of Figure $4 \mathrm{~d}$ and no significant onshore-oriented sediment flux is seen in the suspension region for $z / \eta>2$ in Figure 4e, for sequences $\mathrm{E}$ and $\mathrm{F}$.

[22] Figures $4 \mathrm{f}$ and $4 \mathrm{~g}$ represent the flow, SSC and sediment flux fields in the wave cycle close to the wave crest $u_{+}$, sequences $\mathrm{H}$ and $\mathrm{J}$, and close to the wave trough $u_{-}$, sequence I. Compared to the sequences close to the flow reversals $u_{+r}$ and $u_{-r}$ the 2 -D velocity fields reveal a spatial homogeneity along the ripple shape both in vertical and cross-shore directions. The spatial fluctuations in SSC seen in Figure $4 \mathrm{f}$ are attributed to turbulent events due to strong bed friction effects around $u_{+}$and $u_{-}$. The associated sediment flux fields in Figure $4 \mathrm{~g}$ show intense near-bed zones matching the high near-bed load zones seen in Figure $4 \mathrm{f}$. Again, suspended sediment fluxes due to turbulent bed friction effects are oriented in the same direction as the intense near-bed fluxes. However, these suspension events are limited to a height between $1 \eta$ and $2 \eta$ above the ripple crest whereas the sand cloud entrained into suspension by the lee-side vortex after $u_{+r}$ reached a height of about $4 \eta$ (see Figure 4c).

[23] In conclusion, the occurrence of ripple generated vortices on both the lee and the stoss sides of the ripple is evidenced by the instantaneous fields at the intrawave and intraripple scale shown in Figure 4. The contribution of the lee-side vortex to the offshore-oriented sediment flux is clearly stronger than the contribution of the stoss-side vortex to the onshore-oriented suspended sediment flux. This asymmetric sediment transport contribution is attributed to the high degree of velocity asymmetry in the shoaling zone. Sato and Horikawa [1986] and van der Werf et al. [2007] obtained similar results for highly skewed velocities in oscillatory water tunnel experiments. The shoaled surface gravity waves studied herein seem to induce similar asymmetric ripple vortex entrainment processes.

\section{Intrawave Flow and Sediment Transport Characteristics}

\subsection{Velocity Phase Lagging Along the Ripple Profile}

[24] Wave velocity phase lagging due to increasing inertia effects with distance from the bed occurs in the WBL under laminar and turbulent flow regimes [Nielsen, 1992]. The measurements and ability to model these phase lags for each type of sediment transport regime (bed load, suspension, ripple vortex, sheet flow) is crucial for reliable prediction of the net sediment transport [Dibajnia and Watanabe, 1998; Ribberink et al., 2008]. For the laminar flat bed case it can be shown analytically that the near-bed oscillatory flow leads the free streamflow velocity by $45^{\circ}$ (equivalent to $\delta T / T=$ 0.125 ) whereas for turbulent rough flow conditions the much stronger bed friction induced turbulent eddy viscosity leads to smaller phase lags measured typically in the range of $15^{\circ}-30^{\circ}$ (equivalent to $\delta T / T=0.05-0.10$ ). These phase lag values are typical for rough flat bed where bed friction effects dominate the turbulent shear stress production. In the case of ripple vortex regime, phase lagging due to both bed friction effects and ripple vortex entrainment effects can occur with different roles and impacts on the net sediment transport [van der Werf et al., 2006]. All phase shifts discussed below are computed as $\delta T(z) / T$ where $T$ is the wave period $(6.5 \mathrm{~s})$ and $\delta T(z)$ cor- 
responds to the time shift between a specific event (for example the flow reversal $u_{+r}$ ) occurring at a specific distance $z$ from the ripple crest and the same event occurring outside the ripple affected flow region (taken here at $z=6 \eta$ ). $\delta T(z)$ is positive and negative for a phase lead and lag, respectively.

[25] In this section the cross-shore wave velocity below, above and across the wave boundary layer, WBL, is considered over the wave period at 4 different locations along the ripple profile. To assess the velocity phase lags with $z$, data was analyzed at $u_{+}, u_{-}, u_{+r}$ and $u_{-r}$. In order to assess the spatial variability of the phase lag along the ripple profile, four locations shown in Figure 5a were selected, A, B, C and $\mathrm{D}$ corresponding to the positions at the stoss-side vortex, the ripple crest, the lee-side vortex and the ripple trough. As previously, the velocities have been phase averaged over four consecutive waves and the four relative phase lags $\delta T / T$ correspond to the relative time shifts between $u_{+}, u_{-}, u_{+r}$ and $u_{-r}$ with $z$ and the corresponding velocity outside the bed influenced region taken at $z / \eta=6$.

[26] For the phase lag around $u_{+r}$ it clearly appears that at locations $\mathrm{A}$ and $\mathrm{D}$, somewhat distant from the leeside ripple vortex generation, the phase lead in wave velocity is limited to a near-bed region of about $1 \eta$ (for A) and $2.75 \eta$ (for D) above which the vertical velocity gradient becomes negligible. At location $\mathrm{C}$ where the lee-side vortex is generated, the phase lead reaches a maximum value of $\delta T / T \approx 0.2$ and it decreases linearly with distance from the bed up to a height of $4.5 \eta$ where it becomes negligible. Such a high level is also reached at location $\mathrm{B}$ and a very similar linear decrease in phase lead can only be distinguished at location A for $u_{-r}$ over a vertical distance of up to $3 \eta$. It appears that the phase leads linked to ripple vortex entrainment affects the water column over a greater height above the bed than the phase leads at wave crest and trough due to bed friction effects. Furthermore, the velocity phase leads due to the ripple vortex entrainment show a clear linear decrease with $z$, whereas the phase leads at $u_{+}$and $u_{-}$decreases much faster with $z$, having an exponential type trend and therefore only affecting the water column over a maximum distance of about $1.5 \eta$ from the bed. These results can also be interpreted from the characteristic velocity structure seen in the color plots close to the ripple vortex vortices (seen around $u_{+r}$ at locations B and C, and around $u_{-r}$ at location A). The velocity isolines in the vicinity of the ripple vortices evolve more linearly with $z$ than in regions and at times in the wave cycle without ripple vortices. The fact that at ripple crest (location B), the phase lead and flow structure around $u_{+r}$ are very similar to location $\mathrm{C}$ (at the leeside vortex) can be explained by the ripple shape asymmetry. Indeed, the distance between $\mathrm{B}$ and $\mathrm{C}$ is half the distance A-B and therefore the ripple crest region is strongly affected by the dynamics of the lee side ripple.

[27] The maximum values of $20 \%$ and $10 \%$ obtained here for the phase leads of $u_{+r}$ and $u_{-r}$ at locations $\mathrm{C}$ and $\mathrm{A}$, respectively, can be compared to the average values of $25 \%$ and $18 \%$ obtained in the work of van der Werf et al. [2007] in oscillatory $U$ tube flows above migrating ripples, for nearly similar forcing and wave asymmetry conditions.

\subsection{Mean Velocity, SSC, and Sediment Flux Phases}

[28] In this section the focus is on the ripple-averaged intrawave velocity structure and associated phase lagging of the velocity, SSC and sediment flux. For these results the measurements have been spatially averaged over the ripple profile. The aim is to assess how the characteristic ripple vortex dynamics seen locally in the vicinity of the ripple vortices (detailed in sections 3 and 4.1), impacts on the average flow field and sediment transport processes.

[29] Figure 6a is a color plot of the cross-shore velocity spatially averaged over a ripple wavelength. Figure $6 \mathrm{~b}$ shows the vertical profile of the same velocity phase shifts presented in Figure 5 but calculated for the ripple averaged velocity. It can be seen that the maximum phase lead values obtained here for $u_{+r}$ and $u_{-r}$ are much higher than for $u_{+}$and $u_{-}$. The maximum values of about $5 \%\left(18^{\circ}\right)$ around the wave crest $u_{+}$ and trough $u_{-}$are close to the values commonly measured in the WBL for turbulent rough bed conditions [Nielsen, 1992; Shin and Cox, 2006; Hurther et al., 2007]. This supports the hypothesis that the velocity gradients during maximum onshore and maximum offshore are dominated by turbulent bed shear stress effects. The values of the phase lead due to ripple vortex entrainment are $18 \%$ and $7 \%$ for $u_{+r}$ and $u_{-r}$, respectively. The smaller phase lead of $u_{-r}$ is considered to be as a result of both the strong wave velocity asymmetry and the asymmetry in ripple shape. During the onshore cycle the higher velocity produces a stronger lee-side vorticity and associated shear stress due to the larger vortex compared with the counterpart stoss side vortex generation during the offshore half cycle. This velocity asymmetry effect can explain the differences in phase leads at $u_{+r}$ and $u_{-r}$ for both local and spatially averaged velocities. We attribute the stronger decrease in $u_{-r}$ phase lead between the local and spatial averaged velocity to be due to the much longer, and less steep, stoss side of the ripple which is twice as long as the lee side, see Figure 5a, resulting in reduced dynamic activity on the stoss ripple side and therefore its impact on the spatially averaged velocity was weaker.

[30] Figures 6c and 6d are the color plots of the SSC and the cross-shore sediment flux measured, respectively. In order to discuss the phase shifts of the peak SSC and sediment flux events relative to the wave velocity events $u_{+r}, u_{-r}, u_{+}$, and $u_{-}$, the flow events are represented by the thick solid and dashed lines in Figures $6 \mathrm{c}$ and 6d. It appears clearly in Figure $6 c$ that the maximum suspension event for $z / \eta>0.5$ is due to the lee side vortex produced close to $u_{+r}$ in the near-bed region and its subsequent entrainment into suspension region. As a result, the phase lag is small and increases with distance from the bed relative to the $u_{+_{r}}$ period. From the evolution of the concentration peak in height and time, it can be seen that there was an approximate upward oriented vertical velocity of the sediment carried by the lee side sediment laden vortex of about $+7.5 \mathrm{~cm} \mathrm{~s}^{-1}$. As suggested from the instantaneous intrawave data analysis in section 3 , the stoss side vortex at $u_{-r}$ entrains much less sediments into suspension due to the corresponding SSC peak only propagating to a height of $2 \eta$ above the ripple crest. In this case, the phase lag relative to $u_{-r}$ does not increase significantly with $z$.

[31] For the sediment flux events shown in Figure 6d, it can be seen that the lee side vortex contributes to the strongest sediment flux event in the suspension region and is oriented in the offshore direction. In the region between $z / \eta=4$ and $z / \eta=5$, the peak sediment flux is lagging $u_{+r}$ by one third of the time separating $u_{+r}$ from $u_{-}$. The second strongest sediment flux event in the suspension region is attributed to the 

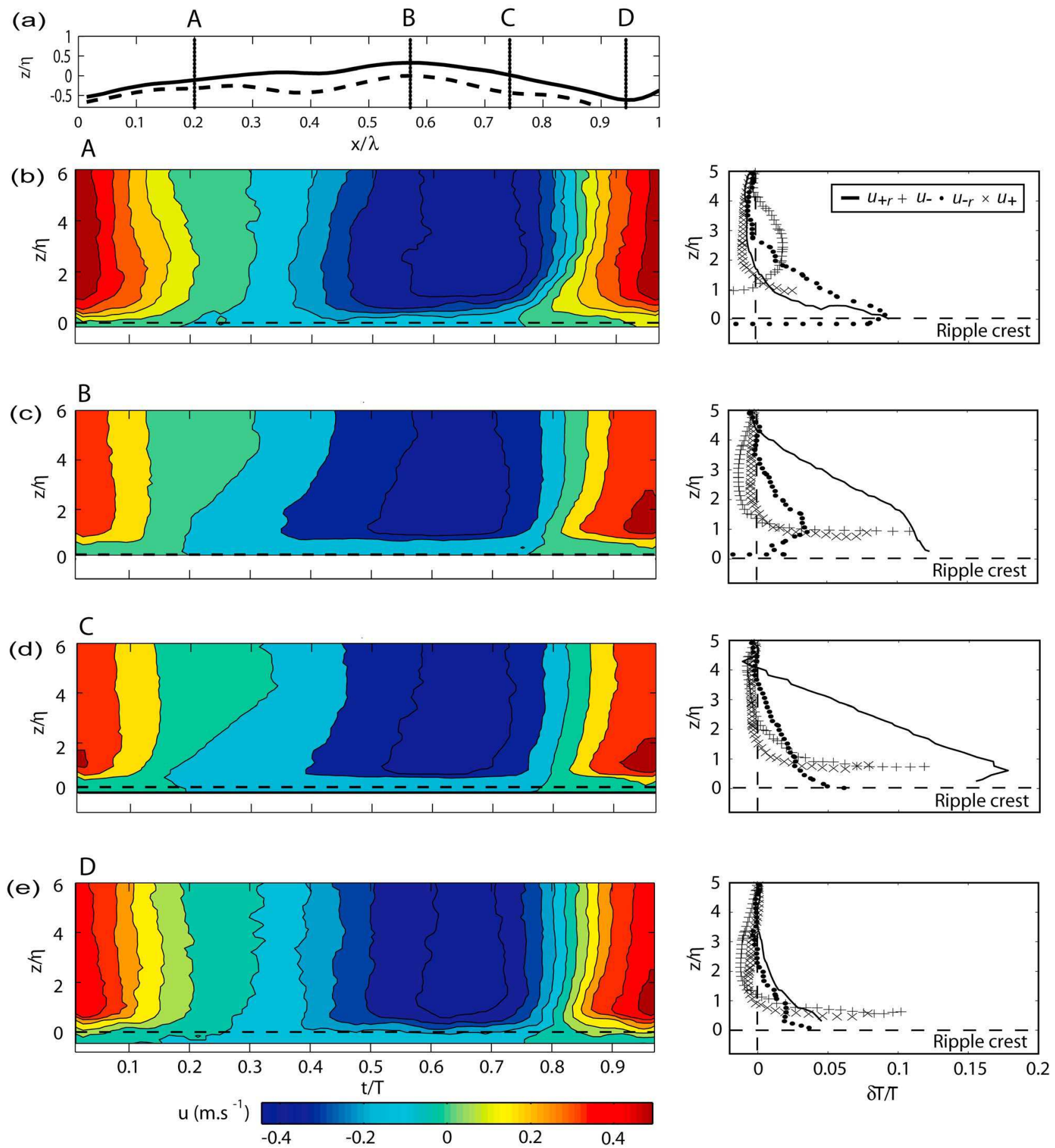

Figure 5. (a) Selected locations along the ripple profile. The solid and dashed lines correspond to the interface between near-bed load and suspension layers and to the nonmoving sand bed, respectively. (b-e) (left) Color plots of the cross-shore velocity over one wave cycle at the selected ripple locations. In each plot the dashed line represents the location of the ripple crest. (right) The vertical profiles of phase shifts of the nearbed velocities at wave crest $u_{+}$(crosses), trough $u_{-}$(plusses), and flow reversals $u_{+r}$ (solid line) and $u_{-r}$ (circles). The phase shifts are relative to the free-stream orbital velocity taken here at $6 \eta$. 

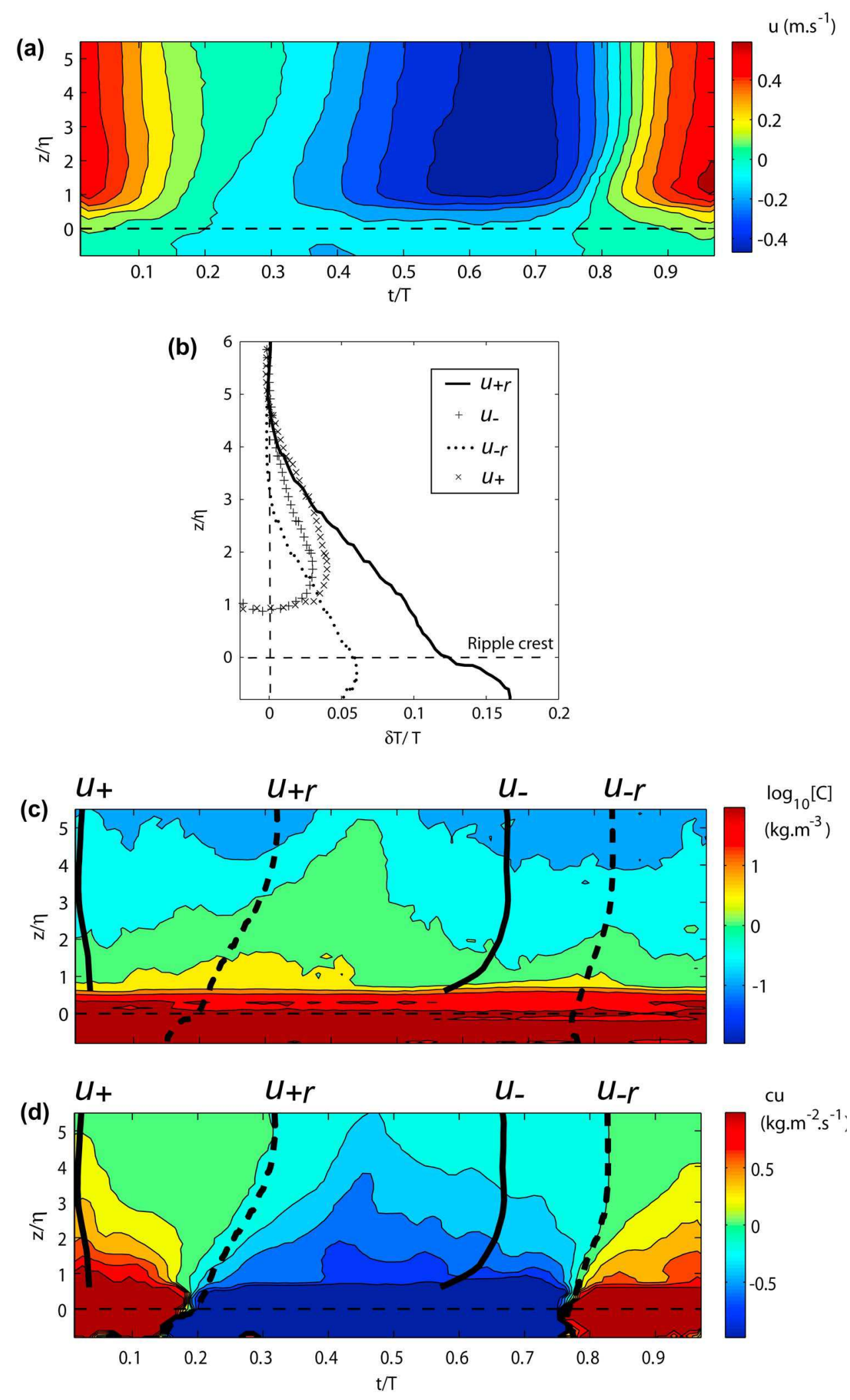

Figure 6. Plots of the spatially averaged (a) cross-shore velocity; (b) vertical profiles for phase at the wave crest $u_{+}$(crosses), trough $u_{-}$(plusses), and flow reversals $u_{+r}$ (solid line) and $u_{-r}$ (circles); (c) $\log _{10}[\mathrm{C}]$ sediment mass concentration; and (d) cross-shore sediment flux over the wave cycle. 

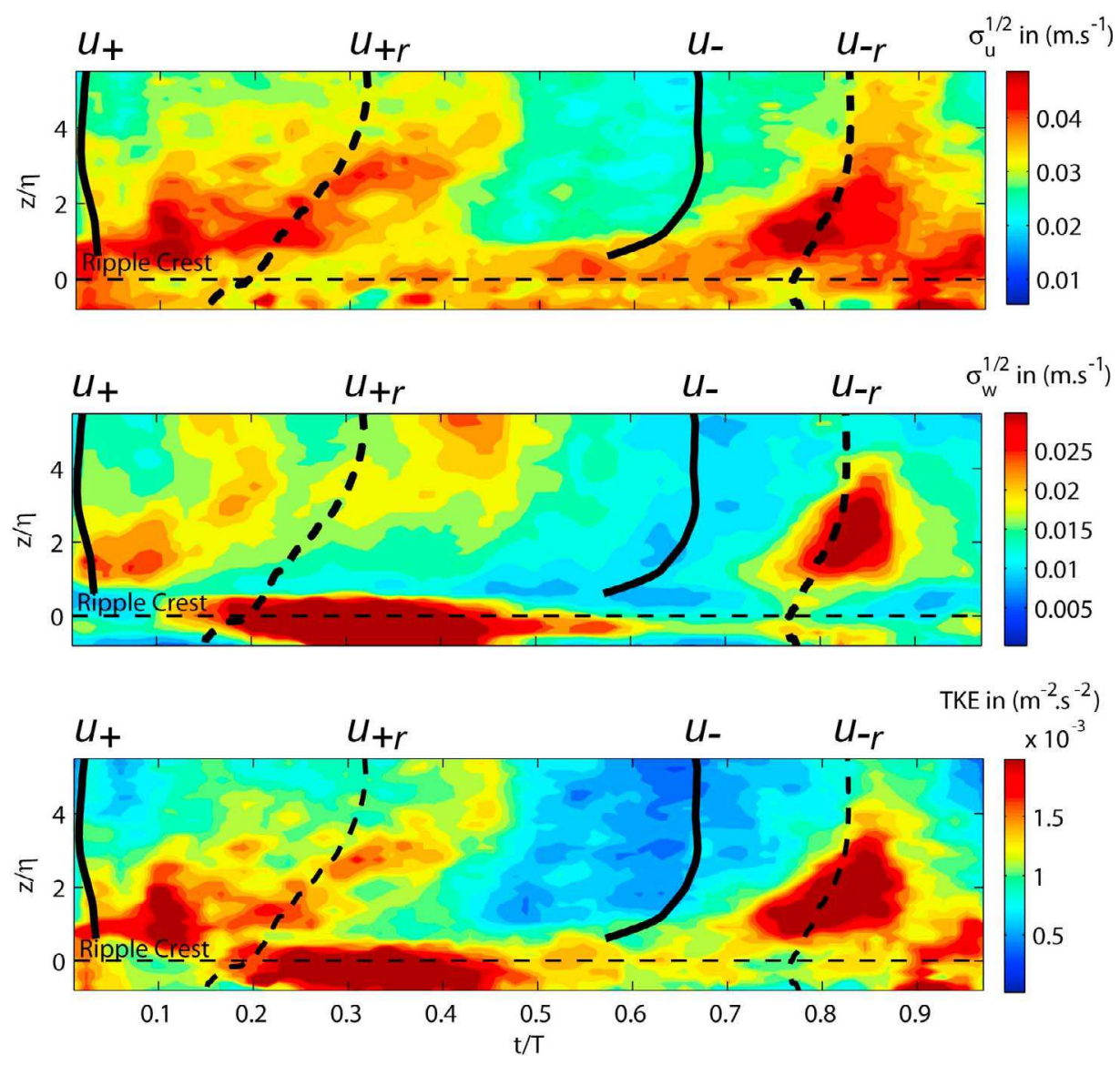

Figure 7. Color plots of the ripple-averaged turbulence intensities over a wave cycle for (top) $u$ and (middle) $w$ components of flow and (bottom) turbulent kinetic energy (TKE). In each plot the solid and dashed lines represent the times of wave crest $u_{+}$, trough $u_{+}$, and flow reversals $u_{+r}$ and $u_{-r}$, respectively.

$u_{+}$event with an onshore-oriented sediment flux. The corresponding peak in sediment flux is in phase with the time of maximum wave velocity.

\subsection{Mean Turbulence Structure}

[32] The calculation of the intrawave distributions of the phase averaged turbulence intensities and the turbulent kinetic energy (TKE) are of primary interest here for the determination of the role and contribution of both the bed friction dominated turbulence in the WBL, and the ripple vortex shedding induced turbulence. For that purpose we will analyze the vertical structure across the near bed load and the suspension regions of the turbulence intensities (square root of the normal Reynolds stresses components)

$$
\sigma_{u}=\left[\overline{(u(t)-\tilde{u}-\bar{u})^{2}}\right]^{1 / 2}=\left(\overline{u^{\prime 2}}\right)^{1 / 2}
$$

and

$$
\sigma_{w}=\left[\overline{(w(t)-\tilde{w}-\bar{w})^{2}}\right]^{1 / 2}=\left(\overline{w^{\prime 2}}\right)^{1 / 2}
$$

in the cross-shore and the vertical directions, respectively. The overbar and tilde notations in the variables represent the time averaged and wave (orbital) components. The TKE was calculated as

$$
T K E=3 / 4\left(\sigma_{u}^{2}+\sigma_{w}^{2}\right)
$$

using

$$
\sigma_{v}=1 / \sqrt{2}\left(\sigma_{u}^{2}+\sigma_{w}^{2}\right)^{1 / 2}
$$

for the approximation of the turbulence intensity in the transverse direction.

[33] The present phase-averaged turbulence quantities were averaged over 91 consecutive waves. In this case we obtained a maximum mean residue of mean Reynolds component $\left|\overline{u_{\max }^{\prime}} \tilde{u}_{\max }\right|$, smaller than $3 \%$. This is sufficiently small to support the validity of the Reynolds decomposition for the velocity. In the present study, the statistical convergence of the Reynolds terms over 4 consecutive waves was not guaranteed and therefore no turbulence data were discussed. As in Figure 6, the thick solid and dashed lines drawn in Figure 7 represent the periods of events at wave crest $u_{+}$, trough $u_{+}$and flow reversals $u_{+r}$ and $u_{-r}$.

[34] The turbulence intensity in the cross-shore direction shown in Figure 7 (top) reveals strong turbulent activity in the suspension region up to a height of about $z / \eta=4$ around both 
flow reversals $u_{+r}$ and $u_{-r}$ with slightly higher levels at $u_{-r}$. As for the SSC and the sediment flux fields in Figures $6 \mathrm{c}$ and $6 \mathrm{~d}$, it seems that the increasing phase lagging in $t / T$ with $z$ relative to the $u_{+r}$ event is the result of the entrainment into the suspension of the turbulence associated with the ripple vortex. This appears since the maximum turbulence intensity increasingly lags in $t / T$ with $z$ for $z / \eta>2$. Again this supports that for the asymmetrical wave conditions in the present study, the dynamics of the stoss side ripple vortex is weaker than for the lee side vortex ripple because the turbulence associated with the stoss side vortex is not seen to persist as long in time and as high in the water column. Strong turbulent activity due to bed friction effects around the $\mathrm{u}_{+}$event can be detected at $t / T=0.1$ and $z / \eta=0.05$ and $t / T=0.95$; $z / \eta=0.05$. In both cases, the flow is only affected up to a height of $2 \eta$ above the ripple crest. Weaker bed friction induced turbulence limited to a maximum height of $1 \eta$ is seen below the $u_{-}$event.

[35] The structure of the turbulence intensity for the vertical velocity is shown in Figure 7 (middle). It differs from the cross-shore component in the near-bed region and the lower part of the suspension region $(z / \eta<1)$. In this region a strong turbulent patch was observed with its center located in between $u_{+r}$ and $u_{-}$. No evidence of noise affected data is associated with this near-bed event. An explanation could be the pressure gradient (flow acceleration)-driven transport process in the near-bed load layer [Sleath, 1987] may be correlated with enhanced near-bed turbulent production. In the suspension region, bed friction induced turbulence can only be clearly seen around the $u_{+}$event between $\mathrm{t} / \mathrm{T}=0-0.2$. Whether the vertical extend with time of this turbulent patch before the $u_{+r}$ line is the result of an ascendant growth is somewhat unclear since it was not clearly observed in the cross-shore component. Finally, as for the cross-shore component, the turbulence due to ripple vortex around $u_{+r}$ and $u_{-r}$ impact the flow field over a much higher distance than the bed friction induced turbulence.

[36] The TKE field presented in Figure 7 (bottom) reveals that the ripple vortex induced turbulence around the $u_{+r}$ and the $u_{-r}$ events are responsible for the turbulence in the upper suspension region up to a maximum height of about $5 \eta$ above the ripple crest. The dominant bed friction induced turbulence occurs in the suspension region for $z / \eta<2$ around the $u_{+}$ event. The stronger bed friction induced turbulence during the onshore half wave cycle can be attributed to the high degree of positive wave asymmetry typical of the shoaling waves. In the near-bed load layer, the more intense patch seen during the $u_{-}$half cycle compared to the $u_{+}$half cycle reveals an asymmetric mean turbulence contribution. Both events seem to be more in phase with the maximum pressure gradient which is known to play a dominant role in the bed load and sheetflow layers [Sleath, 1987; Ribberink et al., 2008].

[37] In the suspension region, the TKE measured during the $u_{+}$half wave cycle both due to bed friction and ripple vortex induced processes, is stronger than during the $u_{-}$half wave cycle. Both of these previous turbulence asymmetries between the two half wave contribute to streaming effects.

\section{Streaming Properties}

[38] The present section is devoted to the analysis of the streaming components measured above the onshore migrat- ing ripple bed under shoaling gravity waves. As previously shown in numerous studies [Trowbridge and Madsen, 1984; Davies and Li, 1997; Nielsen, 2006; van der Werf et al., 2008], different WBL mechanisms driven by the Stokes drift, the acceleration skewness or asymmetric lee and stoss side ripple vortices, can be at the origin of these streaming processes. The estimation of these streaming properties is of primary importance when net sediment transport is addressed.

[39] In the first part of the section, analysis will be presented of the spatial distribution along the ripple profile of the streaming components for the 2-D velocity field, the turbulence intensities and the cross-shore sediment flux. In the second part, the same quantities will be discussed after averaging along the length of ripple transect, resulting in vertical profiles.

\subsection{Spatial Distribution of Streaming Components Along the Ripple Profile}

[40] Figure 8 represents the simultaneous and colocated measurements along the ripple profile of the time averaged $2-\mathrm{D}$ velocity superimposed onto the time averaged sediment concentration. As before, the dashed and solid black lines, respectively, represent the nonmoving sand bed and the lower limit of the suspension region, respectively, measured using the interface detection method described in section 2. Following the procedure used in the PIV measurements presented in the work of van der Werf et al. [2008], the mean spatial-temporal vertical velocity component has been removed. Although, the differences of the plots with and without removing this component are minor, it enhances the visualization of the flow structures seen in Figure 8.

[41] The first and most obvious observation in Figure 8 in the mean flow structure is the vortex like flow patterns on the stoss $(x / \lambda=0.45, z / \eta=0.75)$ and lee sides $(x / \lambda=0.85, z / \eta=$ 0.22 ) of the ripple, with vorticity in opposite directions on either side of the ripple crest. This reveals the high degree of wave-to-wave persistence in time, phase and space of the 2-D velocity field associated with the ripple vortices. The overall structure in mean flow is very consistent with that reported by van der Werfet al. [2007] for skewed oscillating flow. Above the ripple crest, an upward oriented offshore mean velocity can be observed. As shown in the work of van der Werf et al. [2007], this residual offshore upward flow above the ripple crest is due to the stronger return flow associated with the more intense lee-side vortex after the flow reversal $u_{+r}$. Furthermore, as in the work of van der Werf et al. [2007] the ripple shape for high flow asymmetry shows a steeper leeside slope than the stoss side. It is seen that the mean vorticity linked to the ripple vortices affects the highly concentrated near-bed region down to the nonmoving bed. In particular, two erosion patterns at $x / \lambda=0.41$ and $x / \lambda=0.75$, are found below the stoss and lee side vortices. Apart from the previous aspects on flow properties, the strong similarity with the experimental results of van der Werf et al. [2007] strongly supports the validity of the spatial reconstruction method from fixed point ACVP measurements above a migrating ripple bed.

[42] The mean turbulence intensities for the cross-shore and vertical components are represented in Figures 9a and $9 \mathrm{~b}$, respectively. The near-bed structure for $z / \eta<0$ show important differences between the two components. While a 


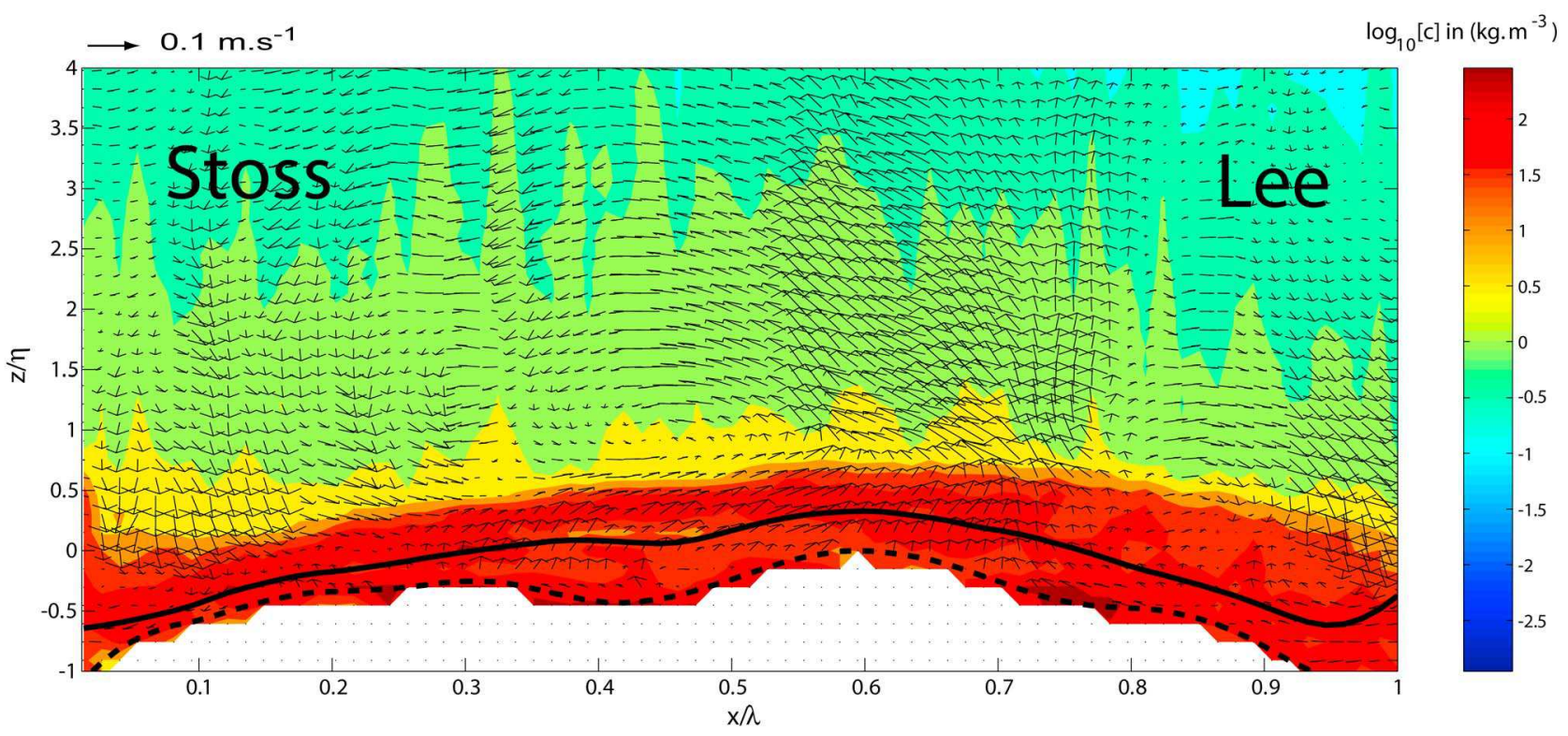

Figure 8. Flow streaming along ripple profile of $V(\bar{u}, \bar{w})$ superimposed on the color plot of $\log _{10}[\mathrm{C}]$ the mean sediment mass concentration. The solid line corresponds to the interface between the suspension layer and near bed load, and the dashed line corresponds to the nonmoving sand bed.

clear turbulence damping effect can be seen in this region all along the ripple profile for the cross-shore component, the vertical component shows a strong turbulence intensity increase in the near-bed load layer particularly on the stoss side of the ripple. From the results obtained in Figure 7 (middle), we deduce that this high near-bed turbulent activity is generated after the flow reversal $u_{+r}$ and before the $u_{-}$ event. In the suspension region of Figure $9 b$, it appears that the strong turbulent events for the vertical component decay much less with $z$ than the strong turbulence patches for the cross-shore intensity component. The vertical extend of these turbulence patches for the cross-shore component (Figure 9a) is restricted to a maximum height of $2 \eta$.

[43] The spatial correspondence between the intense turbulence regions and the mean flow vortices on either side of the ripple crest is rather poor. The differences between crossshore and vertical intensity components in the highly concentrated near-bed region suggest the need for turbulence models to be able to predict strong turbulence anisotropies as well as turbulence damping effects driven by sediment stratification effects across the near-bed layer.

[44] The spatial structure of the streaming components for the cross-shore sediment flux is represented in Figure 9c. In this case, the similarities with the $2-\mathrm{D}$ velocity streaming components in Figure 8 are strong. It appears clearly that the suspended sediment flux is predominantly oriented in offshore direction over $80 \%$ of the ripple profile. The well defined offshore-oriented suspension cloud covers the entire stoss side of the ripple and more than half of the lee side of the ripple profile. It emanates from the region of the lee-side ripple vortex with mean offshore-oriented flow direction as seen in Figure 8. In this region, the offshore suspended sediment flux reaches a maximum value of about $-0.2 \mathrm{~kg} \mathrm{~m}^{-2} \mathrm{~s}^{-1}$. A weaker onshore-oriented suspension flux is measured over a small lee-side fraction $\mathrm{x} / \lambda>0.82$. This region coin- cides with the onshore-oriented part of the lee-side ripple vortex seen in Figure 8. The near-bed sediment flux associated with the near-bed load flux is dominantly oriented in the onshore direction over $70 \%$ of the ripple profile except along a small lee-side fraction for $\mathrm{x} / \lambda>0.7$. Under the present regular shoaling waves conditions, the suspended sediments are generally transported offshore by the asymmetric vortex entrainment process on either side of the ripple crest, while the near-bed load transport is onshore.

\subsection{Profiles of Streaming Components}

[45] In this section the time mean quantities averaged over the ripple profile are presented. As a result vertical profiles will be discussed for two types of cross-shore averaging procedure because of the ripple shape evolution between its trough and crest. Figures $10 \mathrm{a}, 10 \mathrm{c}$, and $10 \mathrm{e}$ were referenced to the ripple crest position which has been taken as the origin of the vertical axis. Figures $10 \mathrm{~b}, 10 \mathrm{~d}$, and $10 \mathrm{f}$ were referenced to the nonmoving sand bed. The solid and the two dashed lines in Figures 10b, 10d, and 10f represent the mean, highest and lowest positions of the suspension/near-bed load interface drawn as the thick solid line in Figures 4 and 8.

[46] Figure 10a represents the spatial-temporally averaged sediment concentration profile referenced to the ripple crest position. For $\mathrm{z} / \eta>1$ the sediment concentration profile has a linearly decreasing trend (on a semilog scale) with distance from the bed. This is a common profile found over rippled beds. A strong increase in concentration is observed just below $z / \eta=1$ with a nominal concentration of about $100 \mathrm{~kg} \mathrm{~m}^{-3}$ at the crest. Between the ripple crest and trough, $-1<\mathrm{z} / \eta<0$, the peak concentration value reaches a maximum of around $200 \mathrm{~kg} \mathrm{~m}^{-3}$. This profile is in overall agreement with the measured and simulated profiles in the work of van der Werf et al. [2008]. The high concentrations, $200 \mathrm{~kg} \mathrm{~m}^{-2}$, reported in the present study were obtained using 

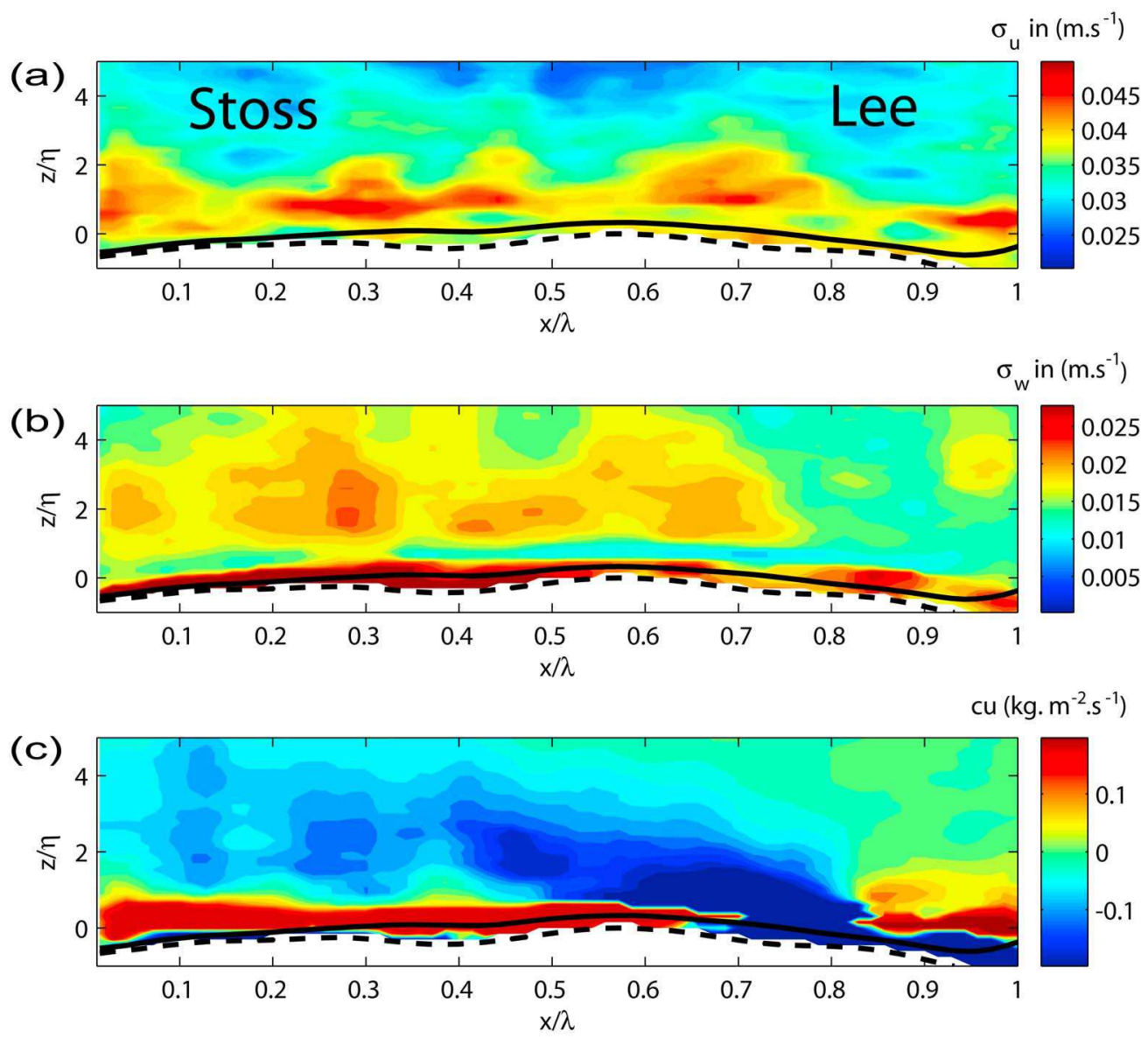

Figure 9. ( $\mathrm{a}$ and $\mathrm{b}$ ) Color plots of the turbulence intensities for the $u$ and $w$ components along the ripple profile. (c) Streaming along the ripple profile for the cross-chore sediment flux $\overline{c u}$. The solid line corresponds to the interface between the suspension layer and near bed load, and the dashed line corresponds to the nonmoving sand bed.

the new dual-frequency inversion described in section 2 [Hurther et al., 2011; Thorne et al., submitted manuscript, 2011], which allows measurement of the concentration to be collected close to the nonmoving sand bed, including the concentration of the sediments contained in the near-bed load layer.

[47] Figure 10b shows a smoother monotonic trend across the near-bed region due to the different referencing method. In this case, the number of samples used in the average is independent of $z$ which leads to a better statistical convergence compared to the ripple crest referencing method. Below the ripple crest, the number of samples decreases with proximity to the ripple trough (when referenced to the ripple crest position as done in Figure 10a) and therefore the average is less accurate from a statistical point of view.

[48] Figures 10c and 10d show the TKE profiles obtained with the different referencing methods. The peak TKE values of $1.5 \times 10^{-3} \mathrm{~m}^{2} \mathrm{~s}^{-2}$ are very similar in both cases. When compared to the results shown in the work of Sato et al. [1987, Figure 10] for $\omega t=3 \pi / 10$, the turbulence intensity for the u component decreases monotonically from a maximum at $\mathrm{z} \cong 0.5 \eta$ down to the rigid bed where a nearly zero value is measured. This nearly zero intensity value is found at the bed for all phases shown in the work of Sato et al. [1987, Figure 10]. In our case, the maximum of turbulence intensity is seen at $\mathrm{z} \cong 1.2 \eta$ (see, e.g., Figures $10 \mathrm{c}$ or $10 \mathrm{~d}$ ) but the maximum decrease of the TKE (about $70 \%$ of reduction) occurs in the zone $1.2 \eta<z<0.5 \eta$ (i.e., well above the nonmoving bed). Furthermore, this zone matches the zone of maximum mean concentration gradient seen in Figure 10a. This further suggests turbulence damping related to sediment stratification effects in the near-bed region. Moreover, this near-bed zone has very low TKE values but the associated net sediment transport is intense with its maximum value at $\mathrm{z} \cong$ $0.0 \eta$. This height is well below the maximum of TKE seen in Figure 10c. This further supports the contribution to near-bed sediment transport by other mechanisms than turbulence, for example intergranular stresses and/or particle collisions.

[49] Finally, the profiles of the streaming component for the cross-shore sediment flux are presented in Figures 10e and 10f. As indicated in Figure 9c, the suspended sediment flux above the ripple crest is predominantly directed offshore due to the strong positive wave asymmetry. The maximum flux value of $-0.14 \mathrm{~kg} \mathrm{~m}^{-2} \mathrm{~s}^{-1}$ in the suspension region is reached at about $z / \eta=2$ followed by a monotonic decrease to zero at $z / \eta=6$. The near-bed change from offshore to onshore 

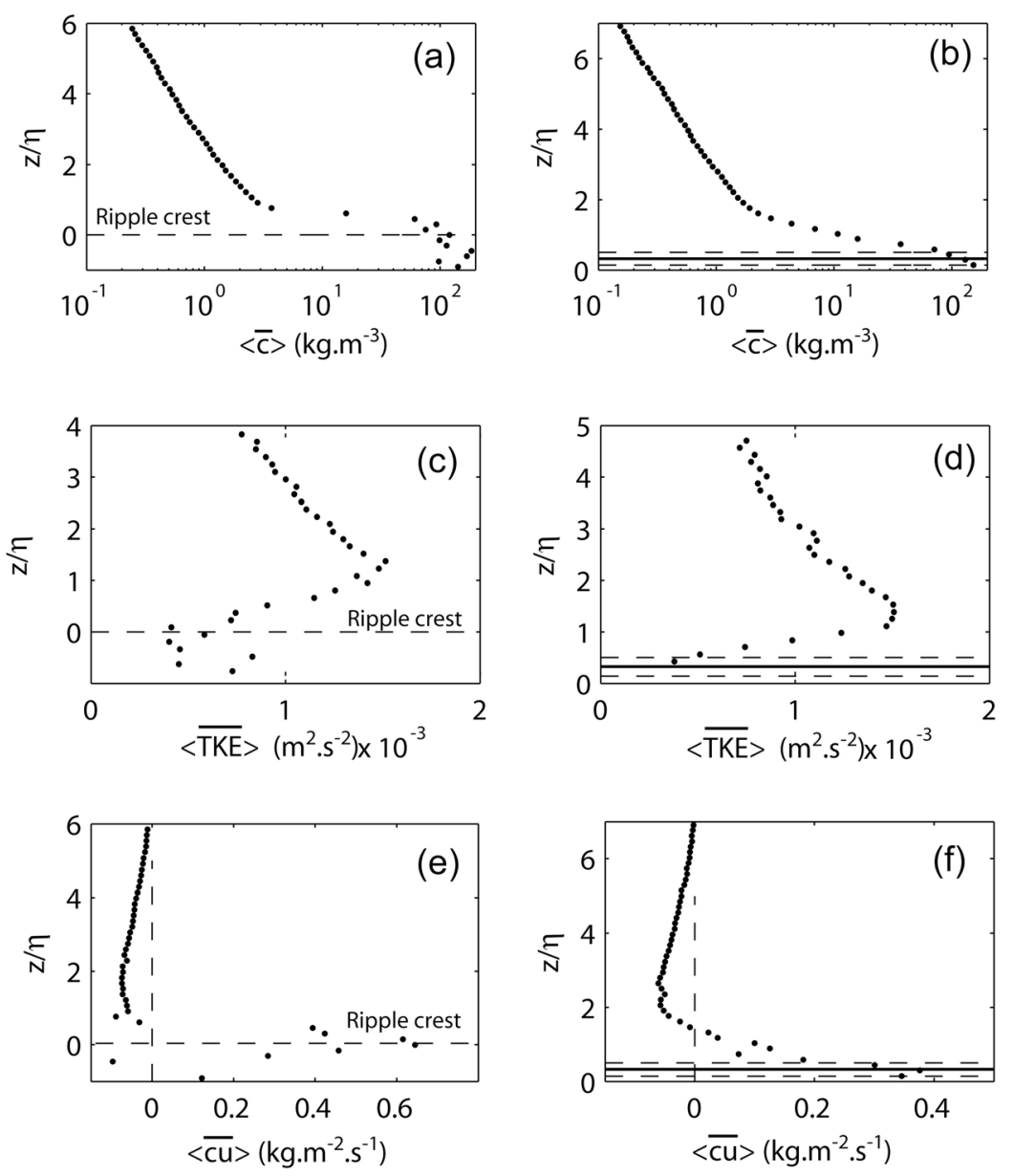

Figure 10. Vertical profiles of ( $\mathrm{a}$ and $\mathrm{b}$ ) the spatial-temporally averaged sediment concentration, (c and d) turbulent kinetic energy (TKE), and (e and f) cross-shore sediment flux. Figures 10a, 10c, and 10e were referenced to the ripple crest, and Figures $10 \mathrm{~b}, 10 \mathrm{~d}$, and $10 \mathrm{f}$ were referenced to the nonmoving sand bed. The overbar and brackets mean that the variables have been time and spatially averaged, respectively.

occurs at $z / \eta=0.05$, which is close to the position of the mean ripple vortices shown in Figure 8. Below this position, a high onshore-oriented sediment flux is measured in agreement with the spatially dominant onshore-oriented near-bed sediment flux obtained in Figure 9c. The maximum value of $0.6 \mathrm{~kg} \mathrm{~m}^{-2} \mathrm{~s}^{-1}$ is reached at the ripple crest. Whether this nearbed sediment flux can be attributed to the bed load sediment flux at the origin of the onshore migrating ripple is discussed in section 6. Again it is quite encouraging to realize that the shape and values above the ripple crest (corresponding to the suspended sediment flux) are in very good agreement with the total suspended sediment flux profile obtained in the work of van der Werf et al. [2007] for their asymmetrical oscillating flow conditions above an onshore migrating ripple bed. As for the concentration and TKE data, the profile shown in Figure 10f calculated using the suspension near-bed load interface is smoother below the ripple crest.

\section{Discussion and Conclusion}

[50] The present study has focused on the details of ripple vortex entrainment processes and their contributions to sed- iment transport under regular shoaling surface gravity waves at nearly full-scale forcing conditions. Measurements using an ACVP, recently developed within the European Union, Hydralab III-SANDS project, were carried out during a series of mobile bed experiments conducted in the large-scale wave channel facility of Canal d'Investigacío i Experimatacío Marítima at the Universitat Poltiècnica de Catalunya (UPCCIEM) in Barcelona. The wave conditions and sediment size were chosen to fill a gap in the full-scale ripple regime conditions as reported in the work of O'Donoghue et al. [2006]. In these conditions, the comparison of the fine-scale and mean dynamics obtained here under shoaling surface waves and in recent studies under asymmetric oscillating $U$ tube tunnel flow, was of primary interest.

[51] In the wave shoaling zone studied, we observed onshore migrating quasi-2-D suborbital ripples for the median sand of diameter $D_{50}=250 \mu \mathrm{m}$ and regular asymmetric waves with a velocity skewness $R=0.61$ used in the experiments. We confirm the occurrence of quasi-2-D/3-D under full-scale wave forcing conditions for ripples as reported in the work of O'Donoghue et al. [2006]. 
[52] On the basis of high-resolution acoustic measurements of the two-component velocity, sediment concentration and sediment fluxes across the suspension region and the nearbed load layer, over a complete ripple profile, a number of processes were identified. These are summarized and considered here. A lee-side ripple vortex process was detected in the flow field measurement before the flow reversal $u_{+r}$. Its subsequent entrainment into the suspension region carries high sediment concentration clouds into the water column up to a height of about $4-5 \eta$ above the ripple crest. Because the lee-side vortex entrainment process occurs at the $u_{+r}$ flow reversal, it predominantly contributes to an offshore suspended sediment flux. A stoss-side vortex was also clearly detected in the flow field before the $u_{-r}$ flow reversal, however, its contribution to sediment entrainment and subsequent onshore sediment transport during the wave crest event, $u_{+}$, was much weaker. This asymmetrical suspended sediment contribution can clearly be attributed to the high wave velocity skewness typical of shoaling waves. Other processes such as bed friction dominated entrainment in the WBL around the wave crest $u_{+}$and trough $u_{-}$events and also contributed to suspended sediment flux, but over a more constrained height of about $1.5-2 \eta$ above the ripple crest.

[53] For the velocity phase lagging it was found that there was a near-bed wave velocity phase lead, relative to the free stream velocity, of up to $20 \%$ of the wave period owing to the lee-side ripple vortex entrainment. This phase shift is much higher than the typical $3-5 \%$ of phase lead due to turbulent rough bed friction effects in the WBL observed around the wave crest and trough events. This value agrees well with the phase lead of $25 \%$ measured by van der Werf et al. [2007] around $u_{+r}$ in a $\mathrm{U}$ tube tunnel with asymmetric oscillatory flows.

[54] The sediment concentration and suspended sediment flux spatially averaged over a ripple profile were maximum in strength in between the $u_{+r}$ and the $u_{-}$events. This contributed to an offshore-oriented transport due to the lee side ripple vortex. The second strongest suspended sediment transport event was onshore sediment flux and occurred around the wave crest event with a lower vertical extend. This event is attributed to bed friction effects at $u_{+}$.

[55] The velocity streaming components below shoaling waves showed the presence of an offshore and upward oriented mean flow above the ripple crest due to the stronger leeside vortex impact on the mean velocity field. This result is in very good agreement with the 2-D mean flow streaming measured with PIV by van der Werf et al. [2008] for their highly skewed water tunnel flow condition. Furthermore it was observed that the mean vortices associated with the leeand stoss-side vortices had an impact on the near-bed load layer since two bed erosion patterns were detected on the ripple profile directly below the vortices.

[56] With regard to the turbulence structure it was possible to distinguish between bed friction induced turbulence in the WBL occurring primarily at wave events $u_{+}$and $u_{-}$up to $2 \eta$ above the ripple crest. Turbulent flow higher up in the suspension region is clearly attributed to ripple vortex turbulence occurring around the flow reversals up to a maximum height of $4.5 \eta$. In the near-bed region, zones of high sediment concentration of up to $200 \mathrm{~kg} \mathrm{~m}^{-3}$ were associated with turbulence damping across the lower suspension region and the near-bed load layer for $z / \eta<1$. Furthermore, turbulence anisotropy between the cross-shore and vertical directions are seen in this region. This suggests the need for Reynolds stress resolving numerical models including stratification effects if these characteristics are to be represented in process based sediment transport models.

[57] It was observed for the vertical distribution of the net sediment transport that the net sediment flux below the ripple crest was onshore with a maximum value four times larger than the maximum offshore net sediment flux in the suspension region. While this offshore suspended sediment flux is driven by the asymmetrical ripple vortex mechanism of the shoaling wave, the near-bed onshore flux is attributed to the near-bed load sediment transport process for the following reason. The mass of sand (per unit channel width) transported in the near-bed load layer over an entire ripple migration period $T_{R}$ was calculated from Figure 10e using $M_{b}=T_{R} \int_{-1}^{L b}$ $\overline{c u} d z=+5.1 \mathrm{~kg} \mathrm{~m}^{-1} . L_{b}$ the upper limit of the near-bed load layer was determined by the mobile bed interface method described in section 2 and the lower limit was the detected nonmoving bed. The value of $M_{b}=+5.1 \mathrm{~kg} \mathrm{~m}^{-1}$ was compared with the value derived from the ripple shape measurements as: $M_{R}=\rho_{s} f \eta \gamma\left(1-\varepsilon_{p}\right)=+5.7 \mathrm{~kg} \mathrm{~m}^{-1}$ where $f$ and $\varepsilon_{p}$ are the ripple shape factor and the sandbed porosity taken here as 0.5 and 0.4 , respectively. The good agreement between the two values strongly suggests that the onshoreoriented sediment flux seen in the near-bed region of Figure 10e corresponds to the near-bed load sediment flux at the origin of the onshore ripple migration. In terms of total net sediment transport, the mass of sand transport in the suspension layer was given by $M_{s}=T_{R} \int_{L b}^{6 \eta} \overline{c u} d z=-2.9\left[\mathrm{~kg} \mathrm{~m}^{-1}\right]$ which is just above half the value of $M_{b}$, resulting in an onshore directed sediment transport of $+2.18\left[\mathrm{~kg} \mathrm{~m}^{-1}\right]$. Therefore, in the present study, the offshore directed suspended sediment transport driven by ripple vortex entrainment is roughly half that of the onshore directed near-bed load transport. In our conditions, the ratio $\eta / D_{50}$ is equal to 116 which is just above the critical value of 90 determined in the work of van der Werf et al. [2006] for oscillatory flow conditions. For values well above 90, van der Werf et al. [2007] measured offshore-oriented total net transport due to the dominant net suspension flux forced by the ripple vortex entrainment process. Dominant offshore-oriented suspension transport could not be reached herein for $\eta / D_{50}=116$ but both the suspension and the near-bed sediment loads are found to be of the same order of magnitude (factor of 1.75). Further experiments under full-scale shoaling waves are needed to analyze the net sediment transport for values of $\eta / D_{50}$ well above the critical value of about 90 .

[58] The results described in this study are not solely about the sediment transport aspects of the work, it also highlights the capability of the ACVP. Using a novel dual-frequency acoustic inversion technique to measure sediment concentration and new near-bed interface detection methods to measure sediment fluxes both through the suspension and the near-bed load layers it has been possible to measure simultaneously with high spatial and temporal resolution collocated the flow, the concentration and the nonmobile bed location. This provides an additional valuable tool for sedimentologist to study detailed boundary layer interface processes. 
[59] Acknowledgments. This study was supported by the European Commission (FP6) project HYDRALABIII-SANDS (EC-022441-RII) and by an ICTS grant from the Spanish Ministry of Education and Science. The authors would like to thank Ivan Caceres, Ben Moate, Richard Cooke, Paul Bell, Jean-Marc Barnoud, and Francois-Xavier Chassagneux for helping to carry out the experiment and Agustín Sánchez-Arcilla for providing the ministry's financial support.

\section{References}

Carstens, M. R., F. M. Nielson, and H. D. Altinbilek (1969), Bed forms generated in the laboratory under an oscillatory flow: Analytical and experimental study, Tech. Memo 28, 39 pp., Coastal Eng. Res. Cent., U.S. Army Corps of Eng., Washington, D. C.

Crawford, A. M., and A. E. Hay (1993), Determining suspended sand size and concentration from multifrequency acoustic backscatter, J. Acoust Soc. Am., 94, 3312-3324, doi:10.1121/1.407237.

Davies, A. G., and Z. Li (1997), Modelling sediment transport beneath regular symmetrical and asymmetrical waves above a plane bed, Cont. Shelf Res., 17, 555-582, doi:10.1016/S0278-4343(96)00048-9.

Dibajnia, M., and A. Watanabe (1998), Transport rate under irregular sheet flow conditions, Coastal Eng., 35, 167-183, doi:10.1016/S0378-3839 (98)00034-9.

Hay, A. E., and J. Sheng (1992), Vertical profiles of suspended sand concentration and size from multifrequency acoustic backscatter, J. Geophys. Res., 97, 15,661-15,677, doi:10.1029/92JC01240.

Hurther, D., and U. Lemmin (2001), A correction method of mean turbulence measurements with a 3D acoustic Doppler velocity profile, J. Atmos. Oceanic Technol., 18, 446-458, doi:10.1175/1520-0426 (2001)018<0446:ACMFTM $>2.0$. CO;2.

Hurther, D., and U. Lemmin (2008), Improved turbulence profiling with field adapted acoustic Doppler velocimeters using a bi-frequency Doppler noise suppression method, J. Atmos. Oceanic Technol., 25, 452-463, doi:10.1175/2007JTECHO512.1

Hurther, D., H. Michallet, and X. Gondran (2007), Turbulent measurements in the surf zone suspension, J. Coastal Res., SI 50, 297-301.

Hurther, D., P. D. Thorne, M. Bricault, J.-M. Barnoud, and U. Lemmin (2011), A multi-frequency Acoustic Concentration and Velocity Profiler (ACVP) for boundary layer measurements of fine-scale flow and sediment transport processes, Coastal Eng., doi:10.1016/j.coastaleng.2011.01.006, in press.

Jaramillo, S. A. Sheremet, M. A. Allison, A. H. Reed, and K. T. Holland (2009), Wave-mud interactions over the muddy Atchafalaya subaqueous clinoform, Louisiana, United States: Wave-supported sediment transport, J. Geophys. Res., 114, C04002, doi:10.1029/2008JC004821.

Lee, T. H., and D. M. Hanes (1995), Direct inversion method to measure the concentration profile of suspended particles using backscattered sound, J. Geophys. Res., 100, 2649-2657, doi:10.1029/94JC03068.

Lofquist, K. E. B. (1978), Sand ripple growth in an oscillatory-flow water tunnel, Tech. Pap. 78-5, 101 pp., Coastal Eng. Res. Cent., U.S. Army Corps of Eng., Washington, D. C.

Nielsen, P. (1992), Coastal Bottom Boundary Layers and Sediment Transport, 324 pp., World Sci., Tokyo.

Nielsen, P. (2006), Sheet flow sediment transport under waves with acceleration skewness and boundary layer streaming, Coastal Eng., 53, 749-758, doi:10.1016/j.coastaleng.2006.03.006.

O'Donoghue, T., J. S. Doucette, J. J. van der Werf, and J. S. Ribberink (2006), The dimensions of sand ripples in full-scale oscillatory flows, Coastal Eng., 53, 997-1012, doi:10.1016/j.coastaleng.2006.06.008.

Ribberink, J. S., J. J. van der Werf, T. O’Donoghue, and W. N. M. Hassan (2008), Sand motion induced by oscillatory flows: Sheet flow and vortex ripples, J. Turbulence, 9, 1-32.

Sato, S., and K. Horikawa (1986) Laboratory study on sand transport over ripples due to asymmetric oscillatory flows, paper presented at 20th
International Conference on Coastal Engineering, Am. Soc. Civil Eng., Taipei.

Sato, S., K. Shimosako, and A. Watanabe (1987), Measurement of oscillatory turbulent boundary layer flow above ripples with a Laser Doppler Velocimeter, Coastal Eng. Jpn., 30, 89-98.

Shin, S., and D. Cox (2006), Laboratory observations of inner surf and swash-zone hydrodynamics on a steep slope, Cont. Shelf Res., 26, 561-573, doi:10.1016/j.csr.2005.10.005.

Sleath, J. F. A. (1987), Turbulent oscillatory boundary flow over tough beds, J. Fluid Mech., 182, 369-409, doi:10.1017/S0022112087002374.

Smyth, C., A. E. Hay, and L. Zedel (2002), Coherent Doppler profiler measurements of near-bed suspended sediment fluxes and the influence of bed forms, J. Geophys. Res., 107(C8), 3105, doi:10.1029/2000JC000760.

Thorne, P. D., and D. M. Hanes (2002), A review of acoustic measurement of small-scale sediment processes, Cont. Shelf Res., 22, 603-632, doi:10.1016/S0278-4343(01)00101-7.

Thorne, P. D., and D. Hurther (2009), Acoustical observations of velocity and suspended sediment structures due to oscillatory flow over a rippled bed, paper presented at 6th International Conference on Coastal Dynamics, Tokyo.

Thorne, P. D., P. J. Hardcastle, and R. L. Soulsby (1993), Analysis of acoustic measurements of suspended sediments, J. Geophys. Res., 98, 899-910, doi:10.1029/92JC01855.

Thorne, P. D., J. S. Davies, and P. S. Bell (2009), Observations and analysis of sediment diffusivity profiles over sandy rippled beds under waves, J. Geophys. Res., 114, C02023, doi:10.1029/2008JC004944.

Traykovski, P. (2007), Observation of wave orbital scale ripples and a nonequilibrium time-dependent model, J. Geophys. Res., 112, C06026, doi:10.1029/2006JC003811.

Traykovski, P., A. E. Hay, J. D. Irish, and J. F. Lynch (1999), Geometry, migration and evolution of wave orbital ripples at LEO-15, J. Geophys. Res., 104, 1505-1524, doi:10.1029/1998JC900026.

Trowbridge, J., and O. S. Madsen (1984), Turbulent wave boundary layers: 2. Second-order theory and mass transport, J. Geophys. Res., 89, 7999 8007, doi:10.1029/JC089iC05p07999.

van der Werf, J. J., J. S. Ribberink, T. O’Donoghue, and J. S. Doucette (2006), Modelling and measurement of sand transport process over full-scale ripples in oscillatory flow, Coastal Eng., 53, 657-673, doi:10.1016/j.coastaleng.2006.02.002.

van der Werf, J. J., J. S. Doucette, T. O'Donoghue, and J. S. Ribberink (2007), Detailed measurements of velocities and suspended sand concentrations over full-scale ripples in regular oscillatory flow, J. Geophys. Res., 112, F02012, doi:10.1029/2006JF000614.

van der Werf, J. J., V. Magar, J. Malarkey, K. Guizien, and T. O'Donoghue (2008), 2DV modelling of sediment transport processes over full-scale ripples in regular asymmetric oscillatory flow, Cont. Shelf Res., 28, 1040-1056, doi:10.1016/j.csr.2008.02.007.

Wiberg, P. L., and C. K. Harris (1994), Ripple geometry in wavedominated environments, J. Geophys. Res., 99, 775-789, doi:10.1029 93JC02726.

Williams, J. J., P. S. Bell, and P. D. Thorne (2003), Field measurements of flow fields and sediment transport above mobile bed forms, J. Geophys. Res., 108(C4), 3109, doi:10.1029/2002JC001336.

Williams, J. J., P. S. Bell, P. D. Thorne, N. Metje, and L. E. Coates (2004), Measurement and prediction of wave-generated suborbital ripples, J. Geophys. Res., 109, C02004, doi:10.1029/2003JC001882.

D. Hurther (corresponding author), Laboratory of Geophysical and Industrial Flows, Université de Grenoble, CNRS, BP 53, F-38041 Grenoble, France. (david.hurther@hmg.inpg.fr)

P. D. Thorne, National Oceanography Centre, Joseph Proudman Building, 6 Brownlow St., Liverpool L3 5DA, UK. 